\title{
Sensitivity Analysis for the Appraisal of Hydrofractures in Horizontal Wells with Borehole Resistivity Measurements
}

\author{
David Pardo* and Carlos Torres-Verdín ${ }^{\dagger}$ \\ *Department of Applied Mathematics, Statistics, and Operational Research, \\ University of the Basque Country (UPV/EHU), Leioa, Spain, and \\ IKERBASQUE (Basque Foundation for Sciences), Bilbao, Spain. \\ ${ }^{\dagger}$ The University of Texas at Austin, Austin TX, USA.
}

(March 27, 2021)

Running head: Hydrofracture Assessment with Resistivity Measurements

\begin{abstract}
This paper numerically evaluates the possibility of using borehole electromagnetic (EM) measurements to diagnose and quantify hydraulic fractures that have been artificially generated in a horizontal well. Hydrofractures are modeled as thin disks perpendicular to the well and filled with either sand-based or electrically-conductive proppant. The study focuses on the effect of both thickness and length (radius) of hydrofractures to assess their effects on specific configurations of borehole resistivity instruments. Numerical results indicate that several measurements (e.g. those obtained with low- and high-frequency solenoids) could be used to asses the thickness of a fracture. However, only low-frequency measurements performed with electrodes and large-spacing between transmitter and receivers (18 m) exhibit the necessary sensitivity to reliably and accurately estimate the length of long hydrofractures (up to $150 \mathrm{~m}$ ) in open-hole wells. In the case of steel-cased wells, the casing acts as a long electrode, whereby conventional low-frequency short-spaced, through-casing
\end{abstract}


measurements are suitable for the accurate diagnosis of long hydrofractures (up to $150 \mathrm{~m}$ in length). 


\section{INTRODUCTION}

Generation of one or several artificial hydrofractures within a well is a common technique to enhance hydrocarbon recovery in tight (low permeability) rock formations. After creating an artificial hydrofracture, it is often necessary to appraise its main geometrical properties, including shape, length, thickness, and principal directions of propagation. The appraisal of a hydrofracture enables the quantification of its benefit in terms of hydrocarbon recovery; it also allows the determination of optimal locations to initiating additional hydrofractures in multi-stage hydrofracturing processes.

The most common technique used for the characterization of hydrofractures is based on microseismic monitoring (see, for example, Warpinski (2009); Song et al. (2010); NolenHoeksema and Ruff (2001)). However, this technique is used only during the stimulation phase of the fracture; occasionally, a posterior assessment may be convenient to appraise the effectiveness of the hydrofracture process. Other acoustic-based methods for hydrofracture diagnosis have been recently proposed in Tang and Patterson (2009) using shear-wave propagation, and in Matuszyk et al. (2011) by examining resonant frequencies. Alternative less common fracture characterization techniques include pressure transient analysis (see Wagenhofer (1996) and references therein).

The main goal of this paper is to study the possibility of accurately estimating thickness and length of long hydrofractures (up to $100 \mathrm{~m}$ ) using borehole EM measurements. Hydrofractures are modeled as disks that are perpendicular and axial symmetric with respect to a horizontal borehole; they may exhibit variable thickness and electrical resistivity. Due to the great depths at which most of these fractures take place and the lossy electrical nature of the Earth's subsurface, we focus only on borehole measurements for detection and 
appraisal, avoiding the use of borehole-to-surface resistivity measurements such as those described in Wang et al. (1991). We also avoid the use of cross-well measurements because a second nearby well may not be available in all reservoirs.

Early results on the diagnosis of open-hole hydrofracture properties using borehole resistivity measurements include the work of Sibbit and Faivre (1985), where large resistive fractures were characterized using dual-laterolog measurements. More recent results invoking different induction logging instruments can be found in Tang et al. (2006); Wang et al. (2005); Xue et al. (2008); Rabinovich et al. (2004); Hu et al. (2010). Because these studies assume acquisition frequencies above $10 \mathrm{kHz}$, the sensitivity of the corresponding resistivity measurements to the length of long hydrofractures is limited.

In contrast to previous studies, this paper considers the case of low-frequency (below 1 $\mathrm{kHz}$ ), and possibly long-spaced antennas. In addition, we consider proppants that exhibit high electrical conductivity as well as conventional proppant made with granular sand. The use of electrically conductive proppants in field operations is not new; they have been used in the past for enhanced hydrocarbon recovery (see Murdoch and Chen (1997)). However, their possible use for fracture characterization has not been exploited yet. In this paper, we assume that electrically-conductive proppant is used to enhance the resistivity contrast between the surrounding rock formation and the hydrofracture itself to increase the sensitivity of borehole resistivity measurements to the hydrofracture's geometrical features.

More importantly, this paper documents for the first time a sensitivity analysis of through-casing resistivity measurements to the presence, thickness, and length of long hydrofractures. An appendix is also included where we describe the main advantages and limitations of using magnetic proppant (see Schmidt and Tour (2009) for a description on 
magnetic proppants) for hydrofracture characterization.

Numerical simulations are performed with a two-dimensional (2D) self-adaptive, goaloriented $h p$-finite element method, where $h$ indicates the element size, and $p$ the polynomial order of approximation, both varying locally throughout the computational grid (for details, see Demkowicz (2006); Pardo et al. (2007a)). This method enables accurate and reliable simulations of resistivity measurements in different borehole environments, including steelcased wells and high contrasts in material properties (see Nam et al. (2008); Pardo et al. (2008b, 2006b, 2007b, 2006a)).

\section{MODEL PROBLEM}

We consider the open-hole model problem described in Figures 1a-1b (horizontal location is higher for the receivers than for the transmitter). When indicated, the well may also possibly incorporate a $1 \mathrm{~cm}$-thick casing with resistivity equal to $2.3 \cdot 10^{-7} \Omega \cdot \mathrm{m}$. Although the geometry of a fracture could be rather complex (e.g., Flekkøy et al. (2002); Gudmundsson and Brenner (2001)), in this paper we assume that its geometry can be described with a perfect disk perpendicular to the borehole. Therefore, in the study we are not concerned with the main direction of propagation of the hydrofracture, which is assumed to be known. The objective of this simplified model is to quantify the limits of spatial resolution of borehole resistivity measurements to basic hydrofracture models. If borehole resistivity measurements are not sensitive to such simple hydrofracture models then it becomes moot to appraise the limits of detectability of the measurements to more complicated models (e.g. multiple adjoining fractures) that may also give rise to electromagnetic clutter.

We consider the following four types of proppant filling the fracture: (a) a sand-based 
proppant such that the resultant hydrofracture resistivity is equal to $0.1 \Omega \cdot \mathrm{m}$, (b) an electrically-conductive coke breeze based proppant with a resultant fracture resistivity equal to $3 \times 10^{-4} \Omega \cdot \mathrm{m}$ (see Graphite (2012)), (c) an electrically-conductive proppant such that the resultant hydrofracture resistivity is equal to $10^{-6} \Omega \cdot \mathrm{m}$., and (d) a ferrite-based proppant such that the resultant hydrofracture relative magnetic permeability is equal to 3 (this type of proppant is analyzed in the appendix). These resistivities assume a clean fracture fullysaturated with proppant. In addition, the highly-conductive proppant cannot be currently manufactured in a cost-effective manner. Several companies are working on the design of more electrically-conductive proppants; we nevertheless include results corresponding to such specific case in this paper because they may serve as additional motivation for the fabrication of more conductive proppants.

In the assumed simple hydrofracture model associated with a horizontal well, fracture thickness is equal to $0.005 \mathrm{~m}$ (unless otherwise indicated). The length of the hydrofracture varies from 0 (no fracture) to $152 \mathrm{~m}$. As subsequently verified in this paper, resistivity measurements are only sensitive to the "conductance" (multiplication of thickness times electrical conductivity) of the hydrofracture. Thus, results shown here also apply to different fracture thicknesses and/or proppant resistivities, as long as the electrical conductance of proppant remains constant.

Sources and receivers. Using cylindrical coordinates $(\rho, \phi, z)$, we consider two types of axisymmetric sources. The first one utilizes solenoidal coils modeled by prescribing an impressed volume electric current density $\mathbf{J}^{i m p}=\delta(z) \delta(\rho-a) I_{J} \hat{\phi}$, where $I_{J}=1$ and $a=0.07$ $\mathrm{m}$ is the radius of the coil, where the resulting electric field is such that $E_{\rho}=E_{z}=0$, i.e.; this source excites only the so-called transverse electric (TE) mode. The second one employs 
electrodes that generate only a $H_{\phi}$ component of the magnetic field i.e., $H_{\rho}=H_{z}=0$ (Transverse Magnetic - TM mode). See Liu et al. (1994) for details. We model this source by prescribing an impressed volume magnetic current density over a coil of radius $0.07 \mathrm{~m}$ whose far-field solution in a homogeneous space is equivalent to that produced by a vertical electric dipole (VED), as described in Pardo et al. (2006b); Lovell (1993).

The corresponding far-field solutions in homogeneous media can be found in Lovell (1993). In practical applications, the effective source intensities depend not only on the circulating electrical current but also on the frequency of operation, number of wire turns in the case of the solenoid, cross-sectional area, perimeter, electrical properties of the core material, and imposed voltage in the case of the electrodes. Simulation results described in this work have not been normalized to reflect measurement conditions. Such a step can only be performed if one were provided with the specific geometric and physical properties of the measurement system.

For open-hole measurements, we assume an acquisition system composed of one transmitter and two receivers. The number of turns/intensity of the second receiver has been adjusted to cancel the total field in resistive (air) media. This technique that is widely used within the logging industry is intended to acquire measurements that are sensitive to the resistivity of the materials in the formation. The spacing between transmitter and receivers is specified in the caption of each figure by two numbers: the first one indicating the distance between transmitter and first receiver, and the second one displaying the distance between first and second receiver.

For steel-cased wells, we employ one transmitter and two receivers measuring the first difference of the axial component of the electric field (parallel to borehole and casing), which 
for low frequencies is equivalent to the second difference of the potential (see Kaufman (1990)). Thus, both receivers have opposite polarizations and measure the electric field at their respective locations without adjusting their intensity. We only consider electrode systems given that solenoidal measurements are inadequate to assess formation properties through casing Kaufman (1990).

It is noted that the logging position displayed in all figures corresponds to the mid-point between the two receivers.

\section{SIMULATION METHOD}

Our simulation method is based on 2D $h p$-Finite Element (FE) discretizations of EM problems. Here $h$ stands for element size whereas $p$ denotes the polynomial element order (degree) of approximation, both varying locally throughout the grid. Our method also incorporates a goal-oriented $h p$ grid refinement algorithm that automatically delivers a sequence of optimal $h p$-grids for each problem. Starting from a given coarse grid, the self-adaptive procedure performs optimal and local $h p$ mesh refinements by minimizing the error of a prescribed quantity of interest (solution at the receivers) with respect to the added number of unknowns. Notice that in resistivity logging measurements it is critical to minimize the error in the quantity of interest rather than in a global norm because the solution at the receivers is typically several orders of magnitude smaller than that near the source, whereby a relatively small (global) absolute error does not necessarily guarantee a small relative error at the receivers.

The main advantage of this goal-oriented grid refinement method is given by the following result: the sequence of grids delivered by the $h p$ goal-oriented adaptive procedure 
converges exponentially fast in terms of the error in the quantity of interest (solution at the receivers) versus the problem size (number of unknowns). Thus, it provides highly accurate solutions using limited computational resources.

The outstanding performance of the $h p$-FE method for simulating diverse resistivity logging measurements as well as its verification has been documented in Pardo et al. (2006a,b, 2007b). A detailed description of the $h p$-FE method and its exponential convergence properties can be found in Demkowicz (2006). We refer to Pardo et al. (2007a) for technical details on the goal-oriented adaptive algorithm applied to electrodynamic simulation problems.

For truncation of the computational domain, we impose a zero Dirichlet boundary condition at $200 \mathrm{~m}$ (for open-hole) or $1000 \mathrm{~m}$ (for steel-cased wells) from the source. This truncation method is customary in most resistivity borehole simulations, thereby making unnecessary the use of more sophisticated methods such as perfectly matched layers Pardo et al. (2008a); Michler et al. (2007). The use of a zero Dirichlet boundary condition is justified by the rapid spatial decay of the EM fields as the observation points recedes away from the source due to the lossy electrical nature of the Earth's subsurface.

\section{NUMERICAL RESULTS}

\section{Open hole wells}

Figure 2a describes the sensitivity of borehole resistivity measurements to the presence and length of an artificially generated fracture filled with sand-based proppant. The measurement system is based on solenoidal coils operating at $100 \mathrm{~Hz}$ in an open-hole horizontal well. Fracture location can be readily identified from the simulated measurements. However, its

length cannot be estimated above $15 \mathrm{~m}$. When employing electrode sources (Figure 2b), 
the sensitivity to the fracture's length decreases even further. As the spacing between transmitters and receivers increases (see Figures 2c and 2d), measurements become more sensitive to the length of the hydrofracture. Regardless of such a behavior, hydrofractures with lateral extent of $61 \mathrm{~m}(200 \mathrm{ft})$ and $152 \mathrm{~m}$ (500 ft) give rise to (almost) identical simulation results for all cases. Therefore, we conclude that the length of long hydrofractures filled with sand-based proppant cannot be accurately estimated using borehole resistivity measurements. Additionally, notice that measurements performed with solenoids exhibit smaller differences than those obtained with electrodes (compare scales of Figures 2a and 2c vs. Figures $2 \mathrm{~b}$ and $2 \mathrm{~d}$ ).

When considering a more electrically-conductive proppant filling the hydrofracture (e.g., coke breeze based proppant), solenoids (Figures 3a and 3c) provide similar (although slightly inferior) results than electrodes (Figures $3 \mathrm{~b}$ and $3 \mathrm{~d}$ ). Electrode-based systems provide the best results in terms of sensitivity with respect to fracture length, and exhibit the necessary sensitivity to discern between a $15 \mathrm{~m}$ and a $61 \mathrm{~m}$ long fracture in the case of long-spaced electrodes (Figure 3d). These differences increase as one increases the electrical conductivity of the proppant filling the hydrofracture, as described in $4 \mathrm{~d}$. Therefore, we conclude that a measurement system based on long-spaced electrodes can be employed to accurately estimate the length of a hydrofracture filled with electrically-conductive proppant.

In the case of an electrically highly-conductive fracture, both real and imaginary parts of the EM fields are sensitive to the presence of a hydrofracture. Furthermore, for long hydrofractures filled with highly-conductive proppants, the imaginary component of the electric field becomes dominant, leading to a shielding effect. Consequently, we observe that the separation of curves corresponding to long hydrofractures decreases in the case of highly-conductive proppant (Figure 4c) compared to the case of coke-breeze based proppant 
(Figure 3c).

Figure 5 shows that the imaginary part has a higher sensitivity to the hydrofracture's length than the real part for the considered cases. In the remainder of the paper, we display only those components of the solution with maximum sensitivity to hydrofracture length. Notice that such components may exhibit a small amplitude compared to the absolute value, whereby the effect of noise should be accounted for in actual field operations, especially at low frequencies.

As emphasized earlier, the sensitivity of measurements to hydrofracture length depends primarily of the electrical conductivity of proppant. There also exist other factors that increase or diminish this sensitivity. Specifically, it is possible to quantify larger hydrofracture lengths by decreasing the frequency of operation (Figure 6a), while an increase in frequency considerably decreases the depth of investigation (Figure 6b) of the measurements. Similarly, an increase of background resistivity (Figure 6c) increases the depth of investigation and increases the conductivity contrast between the formation and background; the opposite effect takes place when decreasing the background conductivity (Figure 6d).

Figures $7 \mathrm{a}, 7 \mathrm{~b}, 7 \mathrm{c}$, and $7 \mathrm{~d}$ describe the sensitivity of measurements to hydrofracture thicknesses and electrical resistivity for a $152 \mathrm{~m}$ long fracture. These results show that measurements are insensitive to variations in hydrofracture thickness and resistivity when the hydrofracture electrical conductance (multiplication of conductivity times thickness) remains constant. 


\section{Steel-cased wells}

In this subsection we consider numerical simulations of $1 \mathrm{~cm}$-thick casing of electrical resistivity equal to $2.3 \cdot 10^{-7} \Omega \cdot \mathrm{m}$. Figure 8 a describes the sensitivity of through-casing resistivity measurements to the presence and length of a hydrofracture filled with sand-based proppant. Results indicate that while the fracture is uniquely identified, its length cannot be accurately estimated when it is greater than $1 \mathrm{~m}$. An increase in proppant electrical conductivity (see Figure 8b), causes the measurements to become more sensitive to hydrofracture length.

Contrary to the case of open-hole measurements, increasing the spacing between transmitter and receivers does not significantly increase the depth of investigation (see Figures 8c and $8 \mathrm{~d}$ ) of the measurements for the case of steel-cased wells. Because casing acts as a long electrode, the depth of investigation of the measurements significantly increases in the presence of steel-cased wells, whereby even conventional (short-spacing) through-casing resistivity measurements become suitable for estimation of long hydrofracture lengths.

Figure 9a indicates that sensitivity of through-casing resistivity measurements to different hydrofracture lengths increases with a decrease in frequency, while an increase in frequency considerably decreases the depth of investigation of the measurements (see Figure 9b). Similarly, an increase of background resistivity (Figure 9c) causes the conductivity contrast and the depth of investigation of the measurements to increase; the opposite effect is achieved when decreasing the background resistivity (Figure 9d). Similar effects are observed with a coke breeze based proppant (see Figures 10a, 10b, 10c, and 10d), as well as in the case of open-hole resistivity measurements.

Figures 11a, 11b, 11c, and 11d quantify the relative differences (in percentage) of the 
effect of hydrofracture properties on the simulated resistivity measurements (i.e., the relative difference of measurements acquired with and without the presence of the fracture in the formation). These results indicate that measurements are sensitive to the presence of a hydrofracture when the latter is filled with an electrically-conductive proppant. Moreover, it is possible to quantify large hydrofracture lengths by employing low-frequency electrodes with an electrically-conductive proppant. This conclusion is valid for both open-hole and steel-cased wells.

\section{CONCLUSIONS}

Numerical simulations indicate that is possible to detect and quantify the thickness and length of single hydraulic fractures with borehole resistivity measurements. The sensitivity of the measurements to hydrofracture properties increases considerably when proppant is electrically conductive (in this case, rock conductivity is enforced through proppant rather than through the fluid filling the space between proppant particles). For the case of open-hole measurements, numerical simulations indicate that long-spaced, low-frequency electrodes are often superior to solenoidal-based systems to quantify hydrofracture properties in horizontal wells. For the case of steel-cased measurements, conventional (possibly short-spaced) low-frequency through-casing measurements exhibit sufficient sensitivity to diagnose hydrofracture properties. Because casing acts as a long electrode, it naturally increases the depth of investigation of the measurements, whereby the use of long-spaced electrodes becomes unnecessary. Such a measurement configuration can be used to accurately assess hydrofracture lengths up to $150 \mathrm{~m}$ provided that both background resistivity and fracture conductance are large enough. However, we note that the depth of investigation of the measurements decreases with an increase of background conductivity and/or 
frequency of operation.

The above conclusions are valid for the case of simple hydrofracture models generated in a horizontal well. Future extensions of this work include the characterization of preferential hydrofracture orientation via three-dimensional borehole resistivity measurements.

\section{ACKNOWLEDGMENTS}

The work reported in this paper was funded by The University of Texas at Austin's Research Consortium on Formation Evaluation, jointly sponsored by Anadarko, Apache, Aramco, Baker-Hughes, BG, BHP Billiton, BP, Chevron, ConocoPhillips, ENI, ExxonMobil, Halliburton, Hess, Maersk, Marathon Oil Corporation, Mexican Institute for Petroleum, Nexen, ONGC, Petrobras, Repsol, RWE, Schlumberger, Shell, Statoil, Total, and Weatherford. The first author was also partially funded under project MTM2010-16511 of the Spanish Ministry of Sciences and Innovation, the Laboratory of Mathematics (UFI11/52) at the University of the Basque Country (UPV/EHU), and the CYTED 2011 project P711RT0278. A note of special gratitude goes to Professor Mukul M. Sharma (University of Texas at Austin) for insightful discussions about hydrofracture properties. We are indebted to Sofia Davydycheva, David Alumbaugh, an anonymous reviewer, and the associate editors for their constructive technical and editorial comments that improved the first version of the manuscript. 


\section{APPENDIX: NUMERICAL SIMULATIONS WITH MAGNETIC PROPPANT}

This appendix considers the case of magnetic proppant, as proposed in Schmidt and Tour (2009). Specifically, we consider two types of proppant. First, a sand- and ferrite-based proppant such that the resultant hydrofracture material properties are: (a) relative magnetic permeability equal to $\mu_{r}=3$, and (b) electrical resistivity equal to $0.1 \Omega \cdot \mathrm{m}$. Second, a coke breeze based proppant with ferrite such that the resultant hydrofracture material properties are: (a) relative magnetic permeability equal to $\mu_{r}=3$, and (b) electrical resistivity equal to $3 \times 10^{-4} \Omega \cdot \mathrm{m}$.

Long-spaced open-hole measurements for the case of sand- and ferrite-based proppant are described in Figures 12a and 12b. Results indicate that using magnetic proppant does not increase the depth of investigation of the measurements. Therefore, hydrofracture length can only be estimated up to at most $10 \mathrm{~m}$ when using this type of proppant.

In the case of a more conductive coke breeze based proppant, the use of ferrite to modify the proppant's magnetic permeability has no significant effect on the simulated measurements (compare Figure $12 \mathrm{~d}$-with ferrite- to Figure $3 \mathrm{~d}$ - no ferrite).

Even for the case of a proppant with relative magnetic permeability as large as 50, further results show that their sensitivity is insufficient to estimate the length of long hydrofractures. Those results have been omitted here for the sake of brevity and because such a high relative magnetic permeability is unavailable in commercial proppants.

The above results indicate that the use of magnetic proppant does not substantially increase the sensitivity of borehole resistivity measurements to estimate hydrofracture length. This behavior arises because the contrast of magnetic permeability between proppant and 
background formation is much lower than that attained with electrical conductivity. 


\section{REFERENCES}

Demkowicz, L., 2006, Computing with hp-Adaptive Finite Elements. Volume I: One and Two Dimensional Elliptic and Maxwell Problems: Chapman and Hall.

Flekkøy, E., A. Malthe-Sørenssen, and B. Jamtveit, 2002, Modeling hydrofracture: Journal of Geophysical Research, 107, 1-11.

Graphite, 2012, Coke Breeze Backfills for Cathodic Protection: www.farwestcorrosion.com/coke-breeze-backfills-by-asbury-graphite.html.

Gudmundsson, A. and S. Brenner, 2001, How hydrofractures become arrested: Terra Nova, 13, 456-462.

Hu, G., I. Geldmacher, and R. Liu, 2010, Effect of fracture orientation on induction logs: A modeling study: Presented at the SPE Annual Technical Conference and Exhibition.

Kaufman, A. A., 1990, The electrical field in a borehole with casing: Geophysics, 55, no. $1,29-38$.

Liu, Q., B. Anderson, and W. Chew, 1994, Modeling low-frequency electrode-type resistivity tools in invaded thin beds: Geoscience and Remote Sensing, IEEE Transactions on, 32, 494-498.

Lovell, J. R., 1993, Finite Element Methods in Resistivity Logging: PhD thesis, Delft University of Technology.

Matuszyk, P., L. Demkowicz, and C. Torres-Verdin, 2011, Sensitivity study to quantify hydrofractures from borehole acoustic waveforms: Presented at the 11th consortium on Formation Evaluation.

Michler, C., L. Demkowicz, J. Kurtz, and D. Pardo, 2007, Improving the performance of perfectly matched layers by means of $h p$-adaptivity: Numerical Methods for Partial Differential Equations, 23, no. 4, 832-858. 
Murdoch, L. C. and J. L. Chen, 1997, Effects of conductive fractures during in-situ electroosmosis: Journal of Hazardous Materials, 55, 239 - 262.

Nam, M. J., D. Pardo, and C. Torres-Verdín, 2008, Simulation of Dual-Laterolog Measurements in Dipping, Invaded and Anisotropic Formations Using a Fourier Series Expansion in a Non-Orthogonal System of Coordinates and a Self-Adaptive $h p$-Finite Element Method: Geophysics., 74, no. 1, E31-E43.

Nolen-Hoeksema, R. C. and L. J. Ruff, 2001, Moment tensor inversion of microseisms from the b-sand propped hydrofracture, m-site, colorado: Tectonophysics, 336, 163-181.

Pardo, D., L. Demkowicz, C. Torres-Verdín, and C. Michler, 2008a, PML enhanced with a self-adaptive goal-oriented hp finite-element method and applications to through-casing borehole resistivity measurements: SIAM Journal on Scientific Computing., 30, 29482964 .

Pardo, D., L. Demkowicz, C. Torres-Verdín, and M. Paszynski, 2006a, Two-Dimensional High-Accuracy Simulation of Resistivity Logging-while-Drilling (LWD) Measurements Using a Self-Adaptive Goal-Oriented $h p$ Finite Element Method: SIAM Journal on Applied Mathematics, 66, no. 6, 2085-2106.

— 2007a, A goal oriented $h p$-adaptive finite element strategy with electromagnetic applications. Part II: electrodynamics: Computer Methods in Applied Mechanics and Engineering., 196, 3585-3597.

Pardo, D., C. Torres-Verdín, and L. Demkowicz, 2006b, Simulation of multi-frequency borehole resistivity measurements through metal casing using a goal-oriented $h p$-finite element method: IEEE Transactions on Geosciences and Remote Sensing, 44, no. 8, 2125-2135. 2007b, Feasibility study for two-dimensional frequency dependent electromagnetic sensing through casing: Geophysics, 72, no. 3, F111-F118. 
Pardo, D., C. Torres-Verdín, and M. Paszynski, 2008b, Simulation of 3D DC borehole resistivity measurements with a goal-oriented $h p$ finite element method. Part II: Through casing resistivity instruments: Computational Geosciences, 12, no. 1, 83-89.

Rabinovich, M., A. Bespalov, B. Corley, G. Merchant, T. Wang, E. Quint, and J. Morrison, 2004, Effect of fractures on multi-component and multi-array induction logs: Presented at the SPWLA 45th Annual Logging Symposium Transactions, Paper UU.

Schmidt, H. K. and J. M. Tour, 2009, Methods for magnetic imaging of geological structures: U.S. Patent 2009/0179649 A1.

Sibbit, A. and O. Faivre, 1985, The dual laterolog response in fractured rocks: Trans, 1-34.

Song, F., H. Kuleli, M. Toksoz, E. Ay, and H. Zhang, 2010, An improved method for hydrofracture-induced microseismic event detection and phase picking: Geophysics, 75, A47.

Tang, X. M. and D. J. Patterson, 2009, Single-well S-wave imaging using multicomponent dipole acoustic-log data: Geophysics, 74, no. 6, WCA211-WCA223.

Tang, Y., T. Wang, B. Corley, and J. Morrison, 2006, Interpreting fracture length from multi-array induction logs: SEG Expanded Abstracts, 25, 421-425.

Wagenhofer, T., 1996, Analytical solutions for hydraulic fracture diagnosis: PhD thesis, The University of Texas at Austin.

Wang, T., J. A. Stodt, D. J. Stierman, and L. C. Murdoch, 1991, Mapping hydraulic fractures using a borehole-to-surface electrical resistivity method: Geoexploration, 28, $349-369$.

Wang, T., X. Tang, L. Yu, B. Kriegshauser, O. Fanini, and G. Ugueto, 2005, Characterizing fractures with multicomponent induction measurements: Petrophysics, 46, 42-51.

Warpinski, N., 2009, Microseismic monitoring: Inside and out: Journal of Petroleum Tech- 
nology, 61, 80-85.

Xue, D., M. Rabinovich, A. Bespalov, and B. Corley, 2008, Characterization of fracture length and formation resistivity from array induction data: Presented at the SPWLA 49th Annual Logging Symposium. 


\section{LIST OF FIGURES}

1 Model problem. . . . . . . . . . . . . . . . .

2 Sensitivity of different logging instruments to the length of a hydrofracture filled with sand proppant. Frequency of operation: $100 \mathrm{~Hz}$. Background (shale) resistivity: $3 \Omega \cdot \mathrm{m} . \ldots \ldots \ldots \ldots$

3 Sensitivity of different logging instruments to the length of a hydrofracture filled with coke breeze based conductive proppant $\left(3 \times 10^{-4} \Omega \cdot \mathrm{m}\right)$. Frequency of operation: $100 \mathrm{~Hz}$. Background (shale) resistivity: $3 \Omega \cdot \mathrm{m} . \quad \ldots . . .$.

4 Sensitivity of different logging instruments to the length of a hydrofracture filled with a highly electrically-conductive proppant $\left(10^{-6} \Omega \cdot \mathrm{m}\right)$. Frequency of operation: $100 \mathrm{~Hz}$. Background (shale) resistivity: $3 \Omega \cdot \mathrm{m} . \ldots \ldots$. . . .

$5 \quad$ Sensitivity of different logging instruments to the length of a hydrofracture. Frequency of operation: $100 \mathrm{~Hz}$. Background (shale) resistivity: $3 \Omega \cdot \mathrm{m}$. Spacing between transmitter and first receiver: $18 \mathrm{~m}$. Spacing between first and second receiver: $1.2 \mathrm{~m} . \ldots \ldots \ldots$

6 Sensitivity of different logging instruments to the length of a hydrofracture filled with a coke breeze electrically-conductive proppant $\left(3 \times 10^{-4} \Omega \cdot \mathrm{m}\right)$. Spacing between transmitter and first receiver: $18 \mathrm{~m}$. Spacing between first and second receiver: $1.2 \mathrm{~m} . \ldots \ldots \ldots$

$7 \quad$ Sensitivity of different logging instruments to proppant thickness and resistivity. Frequency of operation: $100 \mathrm{~Hz}$. Background (shale) resistivity: $3 \Omega$. $\mathrm{m}$. Spacing between transmitter and first receiver: $18 \mathrm{~m}$. Spacing between first and second receiver: $1.2 \mathrm{~m} \ldots \ldots \ldots \ldots$

8 Steel-cased well. Sensitivity of different logging instruments to hydrofracture length. Frequency of operation: $10 \mathrm{~Hz}$. Background (shale) resistivity: $3 \Omega \cdot \mathrm{m} .29$

9 Steel-cased well. Sensitivity of different logging instruments to the length of a hydrofracture filled with electrically-conductive proppant $\left(10^{-6} \Omega \cdot \mathrm{m}\right)$. Spacing between transmitter and first receiver: $1.2 \mathrm{~m}$. Spacing between first and second receiver: $0.3 \mathrm{~m} . \ldots \ldots \ldots \ldots$

10 Steel-cased well. Sensitivity of different logging instruments to the length of a hydrofracture filled with coke breeze based proppant $\left(3 \times 10^{-4} \Omega \cdot \mathrm{m}\right)$. Spacing between transmitter and first receiver: $1.2 \mathrm{~m}$. Spacing between first and second receiver: $0.3 \mathrm{~m} . \ldots \ldots \ldots \ldots$

11 (a,b) Open-hole well, $100 \mathrm{~Hz}$. (c,d) Steel-cased well, $10 \mathrm{~Hz}$. Sensitivity of different logging instruments to hydrofracture length. Background (shale) resistivity: $3 \Omega \cdot$ m. . . . . . . . . . . . . . . . .

12 Open-hole well. Sensitivity of different logging instruments to the hydrofracture length. (a,b) sand and ferrite based proppant. (c,d) coke breeze based proppant with ferrite. Frequency of operation: $100 \mathrm{~Hz}$. Background (shale) resistivity: $3 \Omega \cdot \mathrm{m} . \ldots \ldots \ldots \ldots \ldots$ 


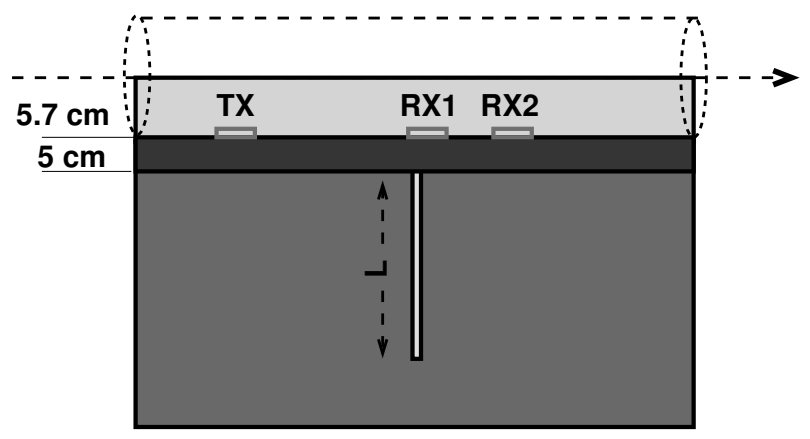

(a) Geometry of the model problem
Fracture Thickness: $0.005 \mathrm{~m}$

Fracture Length $0^{4} \bar{\Omega} \cdot 150 \mathrm{~m}$

lua Resistivity: $1 \Omega \cdot m$

Background Resistivity $3 \Omega$.

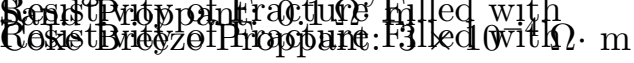

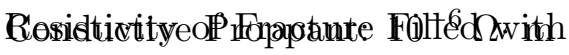

(b) Main properties of the model problem

Figure 1: Model problem. 


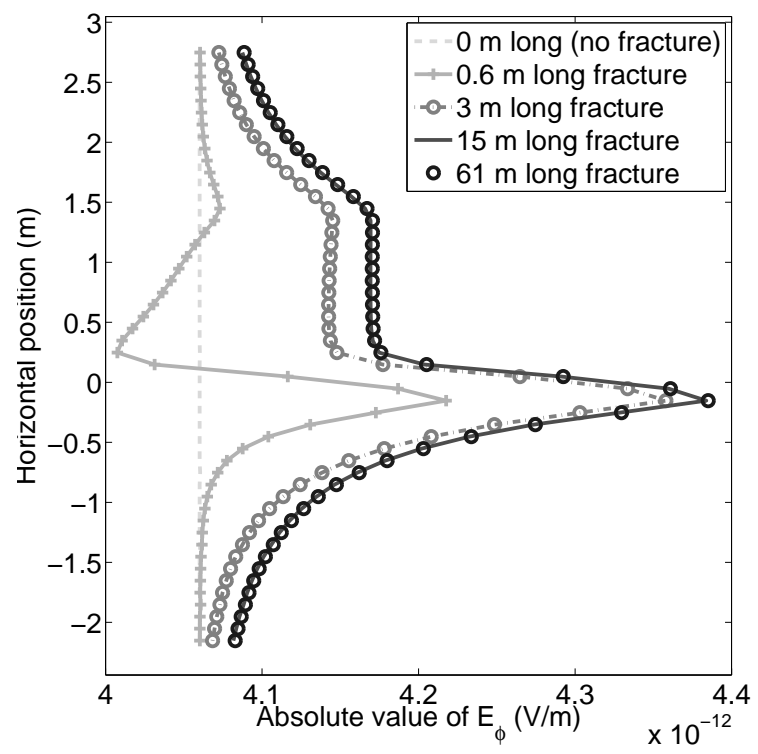

(a) Solenoids, $1.2 \mathrm{~m}-0.3 \mathrm{~m}$ spacing

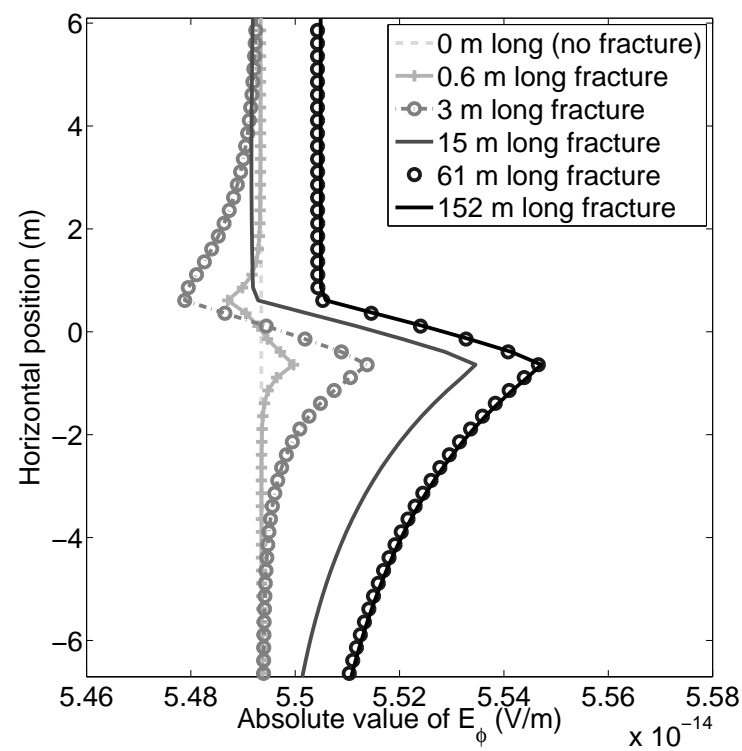

(c) Solenoids, $18 \mathrm{~m}-1.2 \mathrm{~m}$ spacing

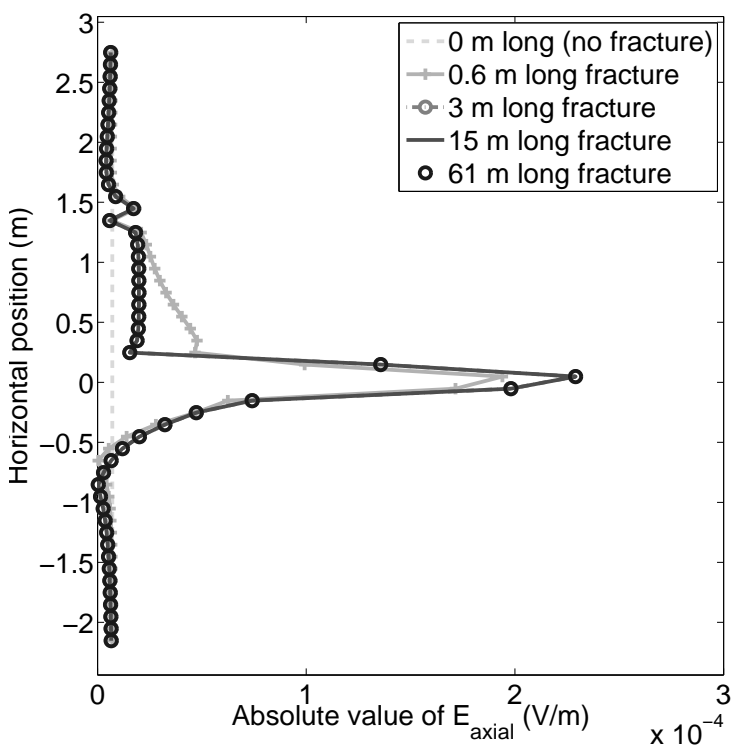

(b) Electrodes, $1.2 \mathrm{~m}-0.3 \mathrm{~m}$ spacing

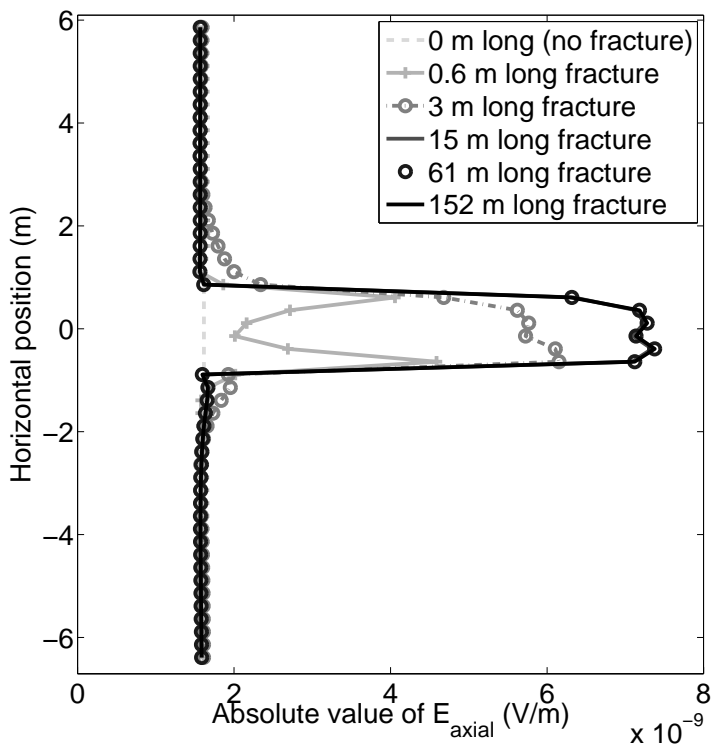

(d) Electrodes, $18 \mathrm{~m}-1.2 \mathrm{~m}$ spacing

Figure 2: Sensitivity of different logging instruments to the length of a hydrofracture filled with sand proppant. Frequency of operation: $100 \mathrm{~Hz}$. Background (shale) resistivity: $3 \Omega$. $\mathrm{m}$. 


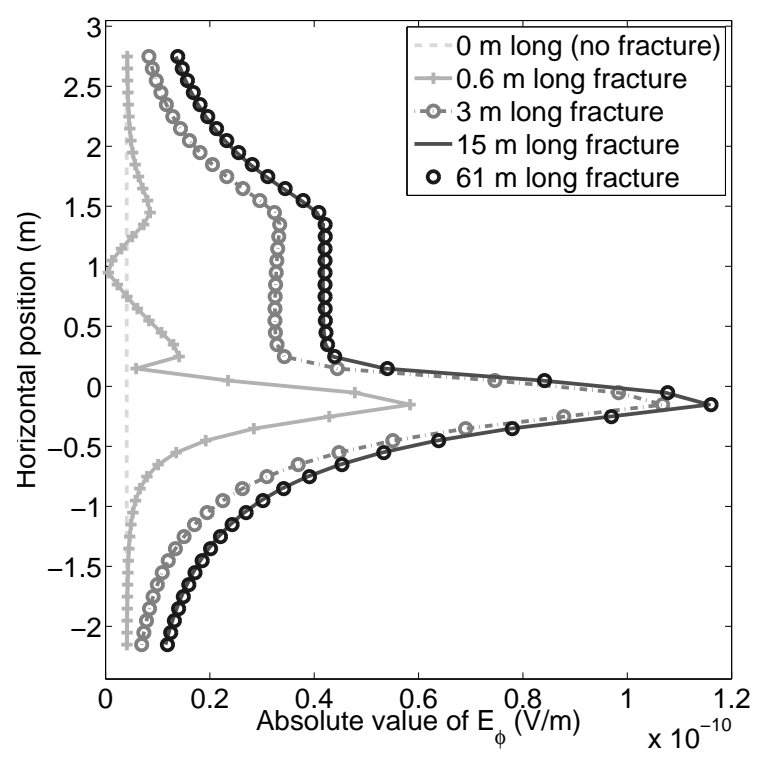

(a) Solenoids, $1.2 \mathrm{~m}-0.3 \mathrm{~m}$ spacing

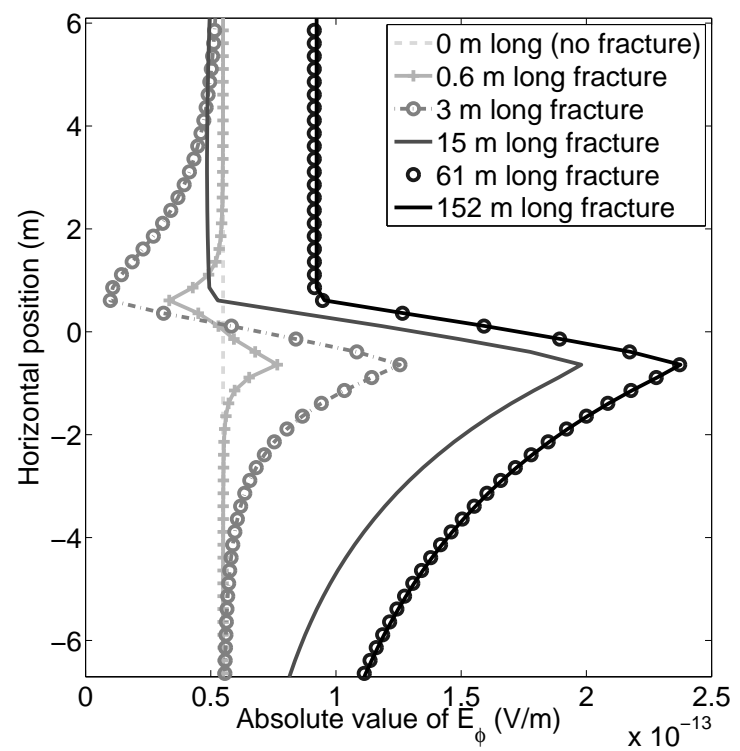

(c) Solenoids, $18 \mathrm{~m}-1.2 \mathrm{~m}$ spacing

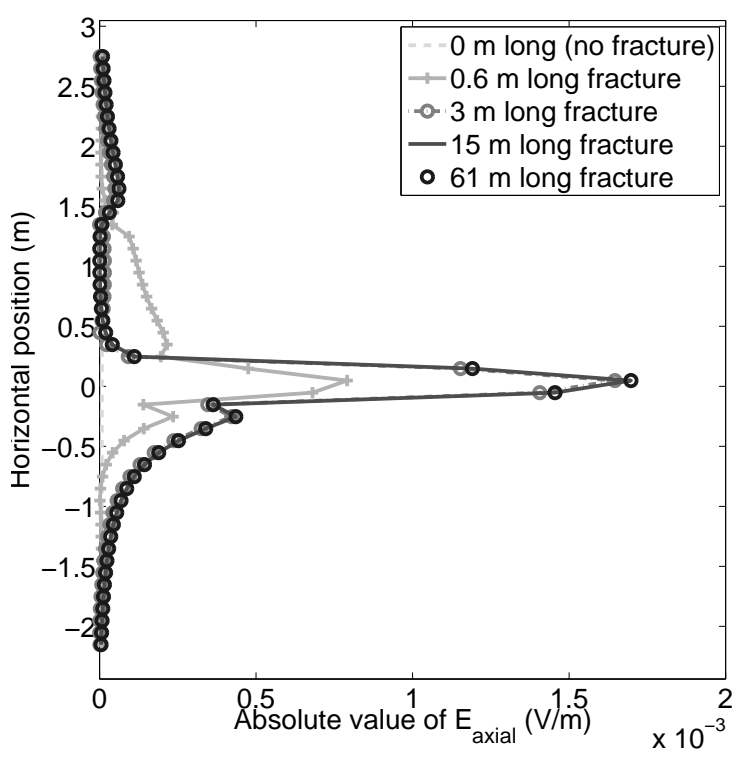

(b) Electrodes, $1.2 \mathrm{~m}-0.3 \mathrm{~m}$ spacing

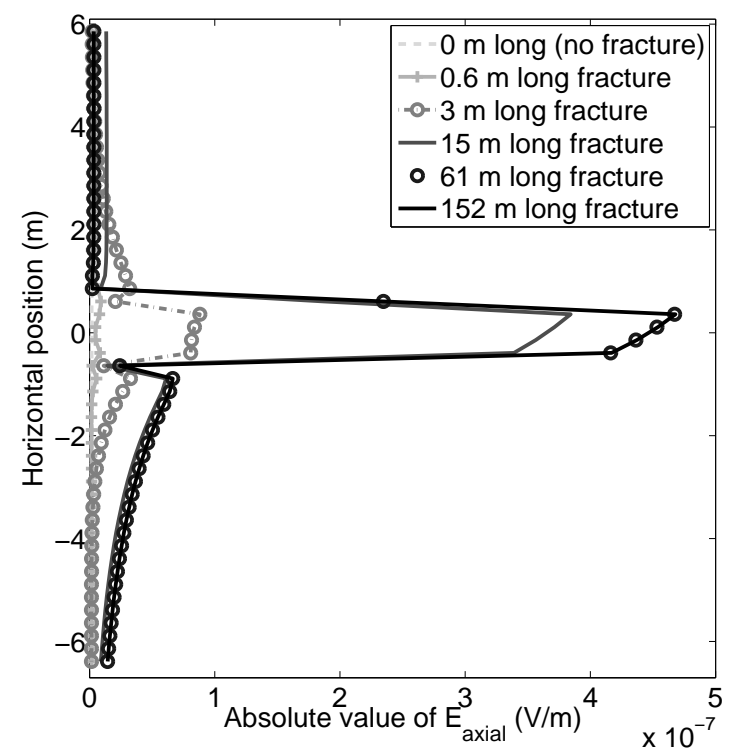

(d) Electrodes, $18 \mathrm{~m}-1.2 \mathrm{~m}$ spacing

Figure 3: Sensitivity of different logging instruments to the length of a hydrofracture filled with coke breeze based conductive proppant $\left(3 \times 10^{-4} \Omega \cdot \mathrm{m}\right)$. Frequency of operation: 100 Hz. Background (shale) resistivity: $3 \Omega \cdot \mathrm{m}$. 


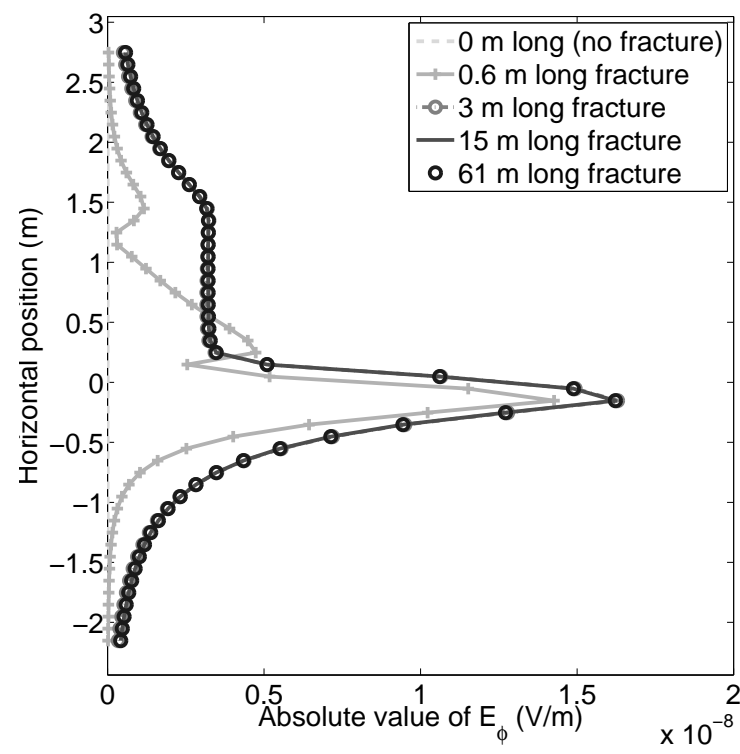

(a) Solenoids, $1.2 \mathrm{~m}-0.3 \mathrm{~m}$ spacing

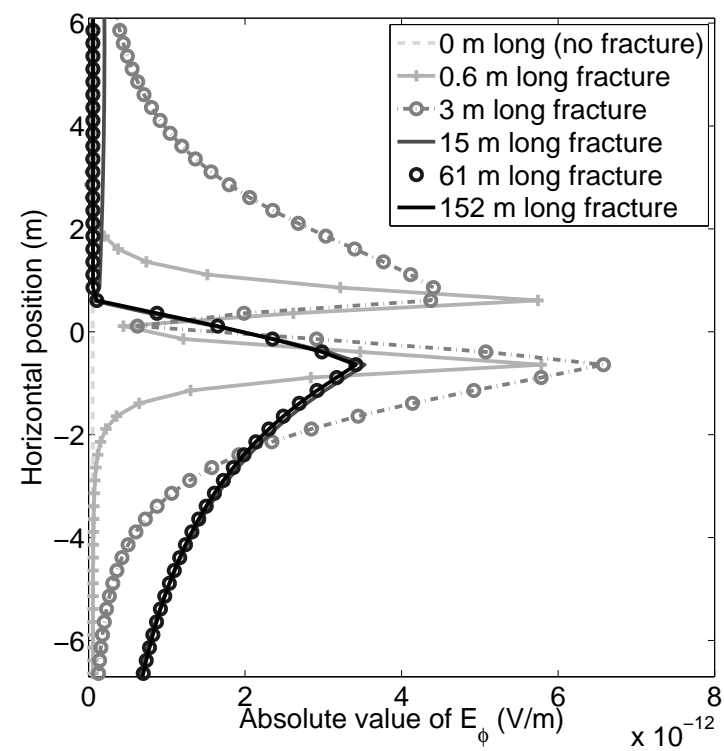

(c) Solenoids, $18 \mathrm{~m}-1.2 \mathrm{~m}$ spacing

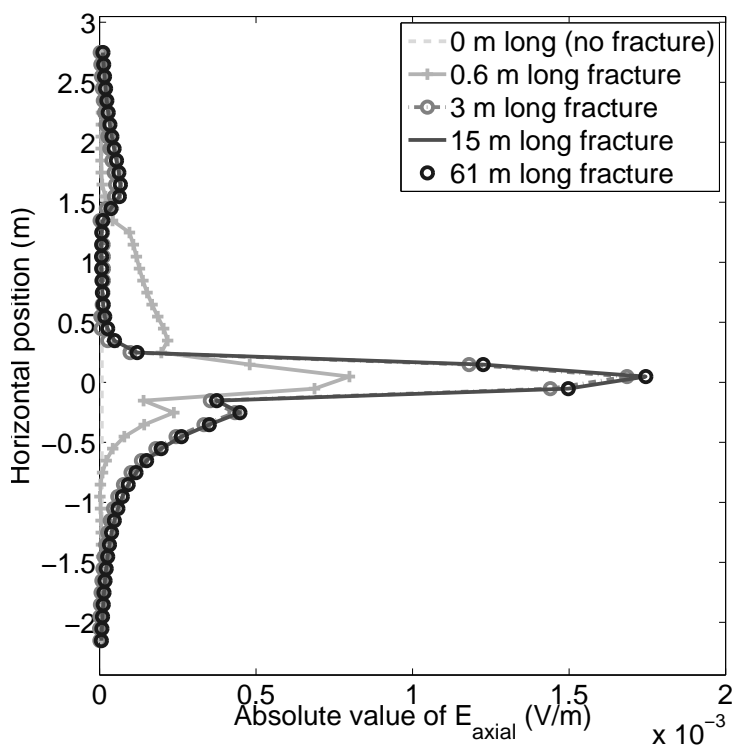

(b) Electrodes, $1.2 \mathrm{~m}-0.3 \mathrm{~m}$ spacing

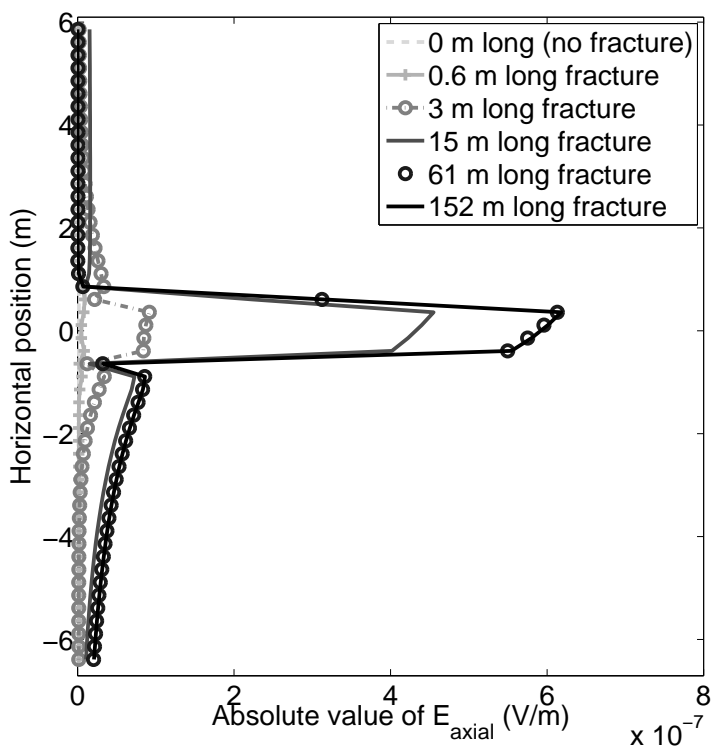

(d) Electrodes, $18 \mathrm{~m}-1.2 \mathrm{~m}$ spacing

Figure 4: Sensitivity of different logging instruments to the length of a hydrofracture filled with a highly electrically-conductive proppant $\left(10^{-6} \Omega \cdot \mathrm{m}\right)$. Frequency of operation: 100 Hz. Background (shale) resistivity: $3 \Omega \cdot \mathrm{m}$. 


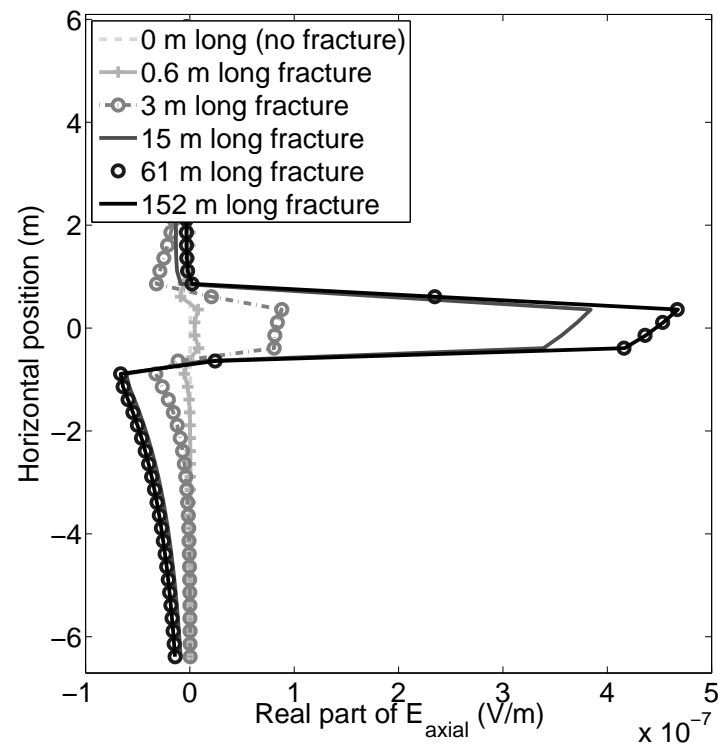

(a) Coke breeze proppant $\left(3 \times 10^{-4} \Omega \cdot \mathrm{m}\right)$

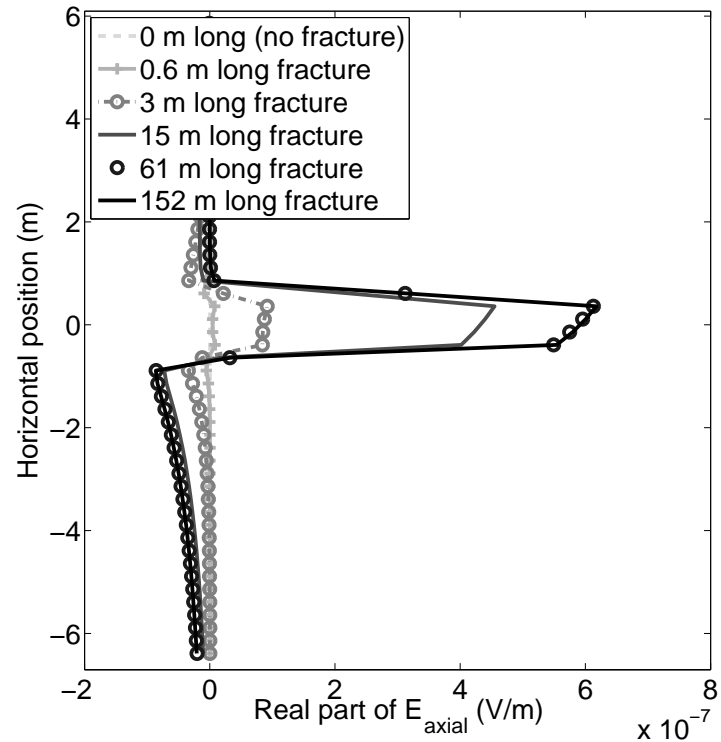

(c) Conductive proppant $\left(10^{-6} \Omega \cdot \mathrm{m}\right)$

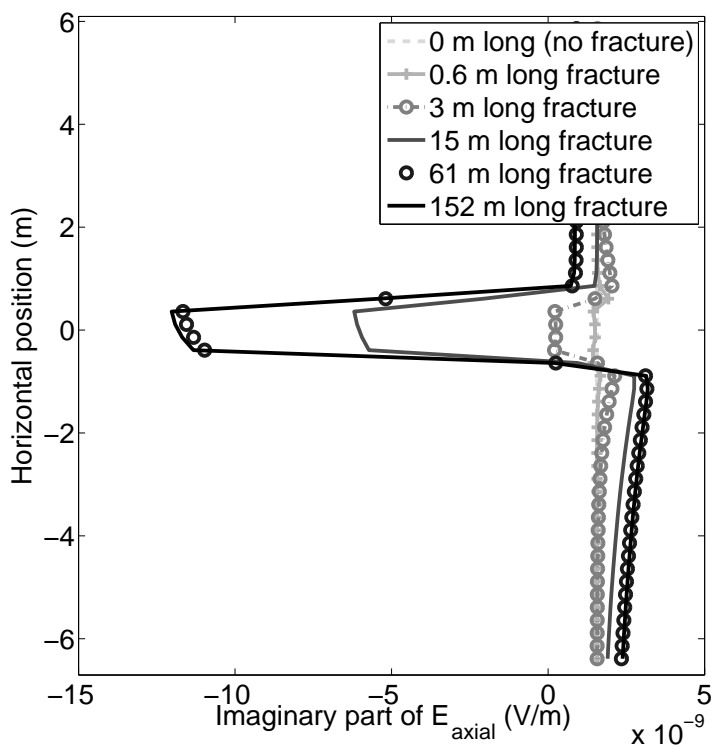

(b) Coke breeze proppant $\left(3 \times 10^{-4} \Omega \cdot \mathrm{m}\right)$

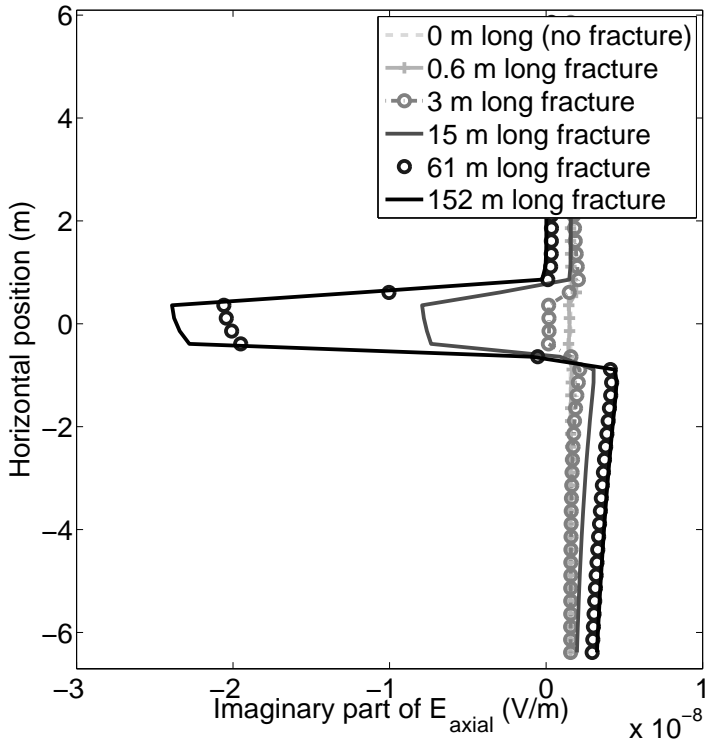

(d) Conductive proppant $\left(10^{-6} \Omega \cdot \mathrm{m}\right)$

Figure 5: Sensitivity of different logging instruments to the length of a hydrofracture. Frequency of operation: $100 \mathrm{~Hz}$. Background (shale) resistivity: $3 \Omega \cdot \mathrm{m}$. Spacing between transmitter and first receiver: $18 \mathrm{~m}$. Spacing between first and second receiver: $1.2 \mathrm{~m}$. 

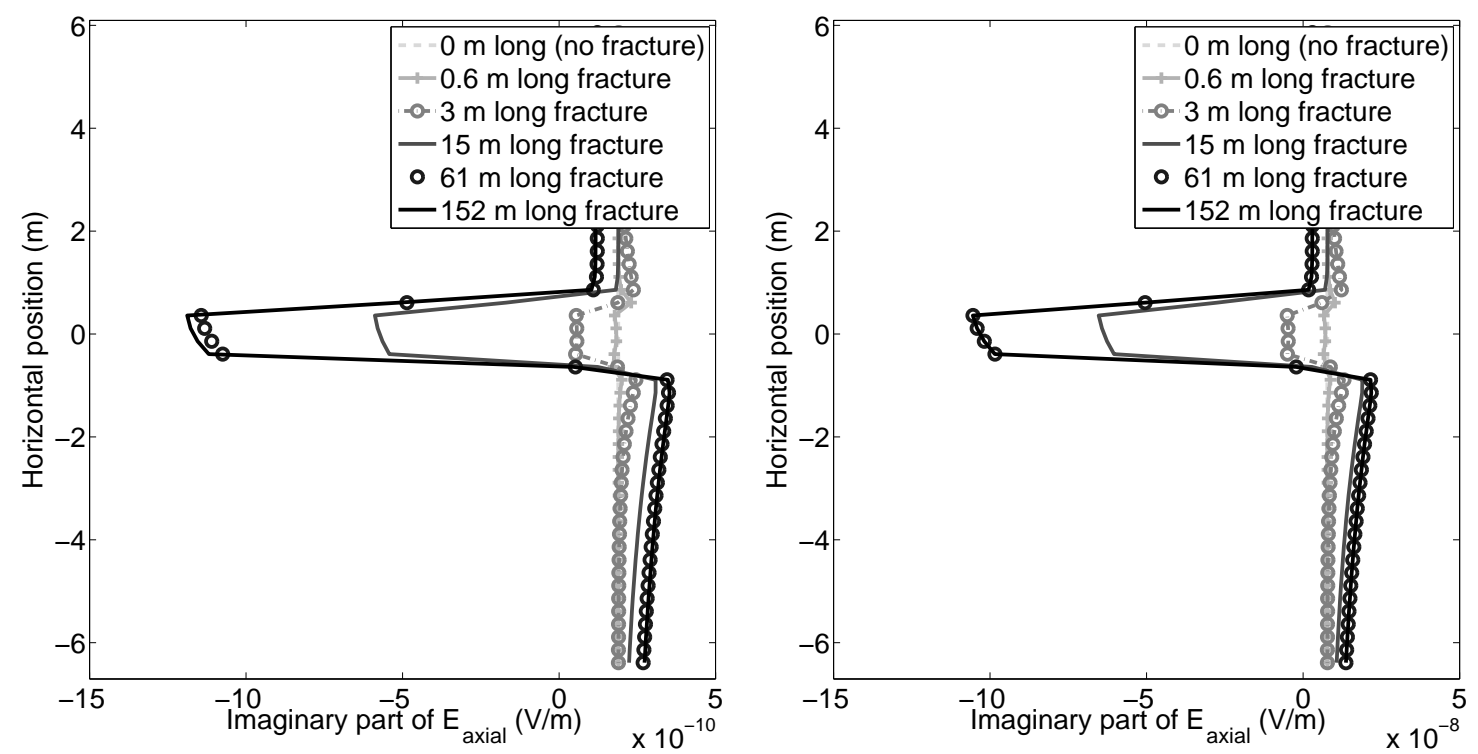

(a) Electrodes, $10 \mathrm{~Hz}$, background resistivity: $3 \Omega \cdot \mathrm{m}(\mathrm{b})$ Electrodes, $1000 \mathrm{~Hz}$, background resistivity: $3 \Omega$.

$\mathrm{m}$
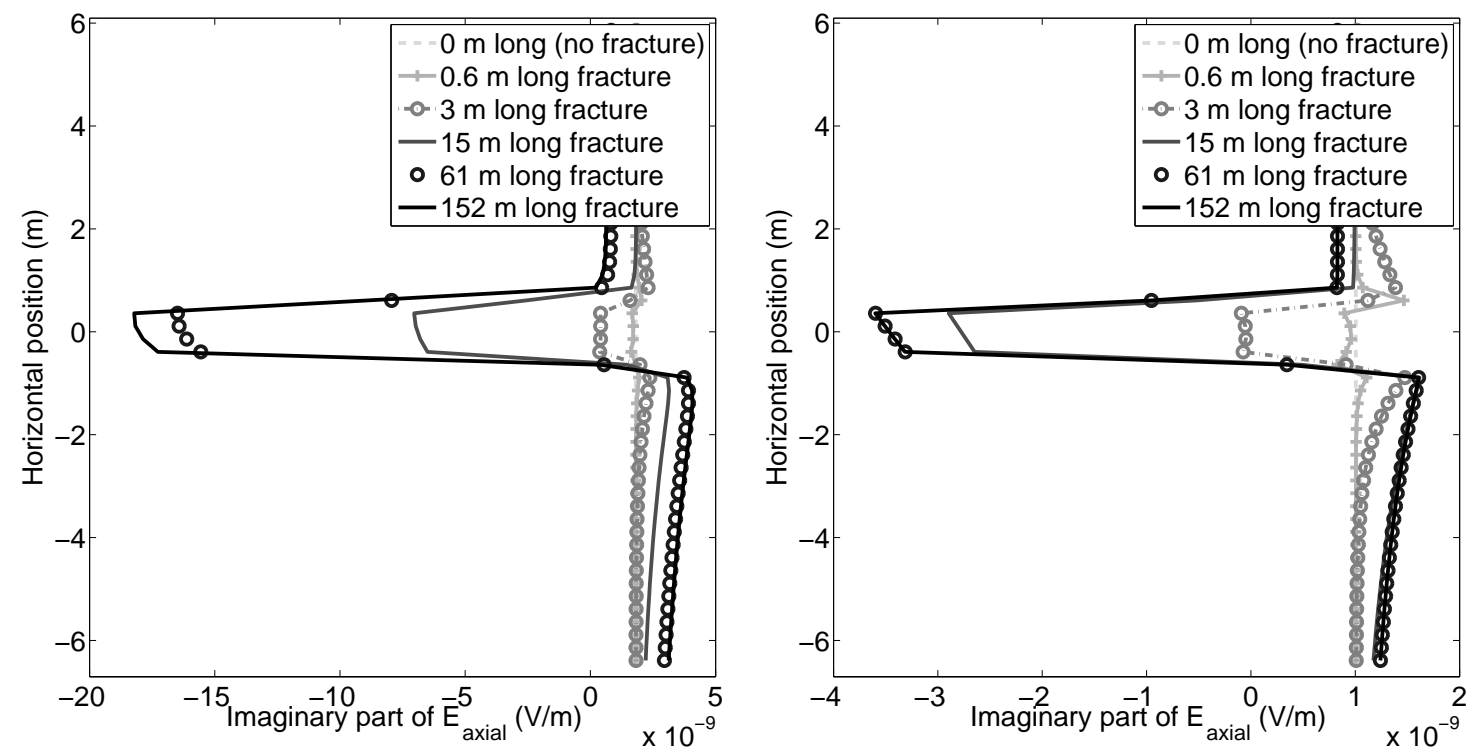

(c) Electrodes, $100 \mathrm{~Hz}$, background resistivity: $10 \Omega \cdot(\mathrm{d})$ Electrodes, $100 \mathrm{~Hz}$, background resistivity: $0.5 \Omega$. $\mathrm{m}$

$\mathrm{m}$

Figure 6: Sensitivity of different logging instruments to the length of a hydrofracture filled with a coke breeze electrically-conductive proppant $\left(3 \times 10^{-4} \Omega \cdot \mathrm{m}\right)$. Spacing between transmitter and first receiver: $18 \mathrm{~m}$. Spacing between first and second receiver: $1.2 \mathrm{~m}$. 


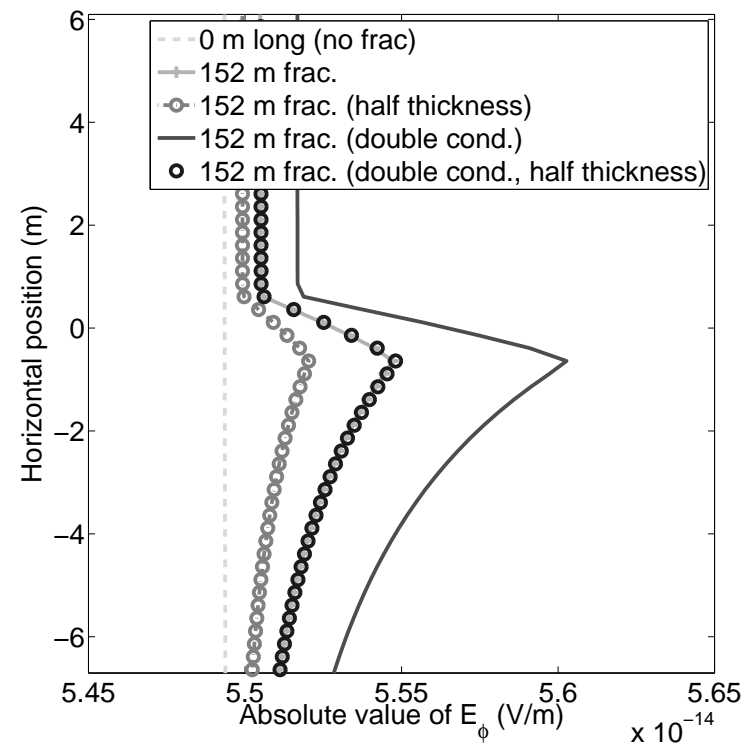

(a) Solenoids, sand proppant

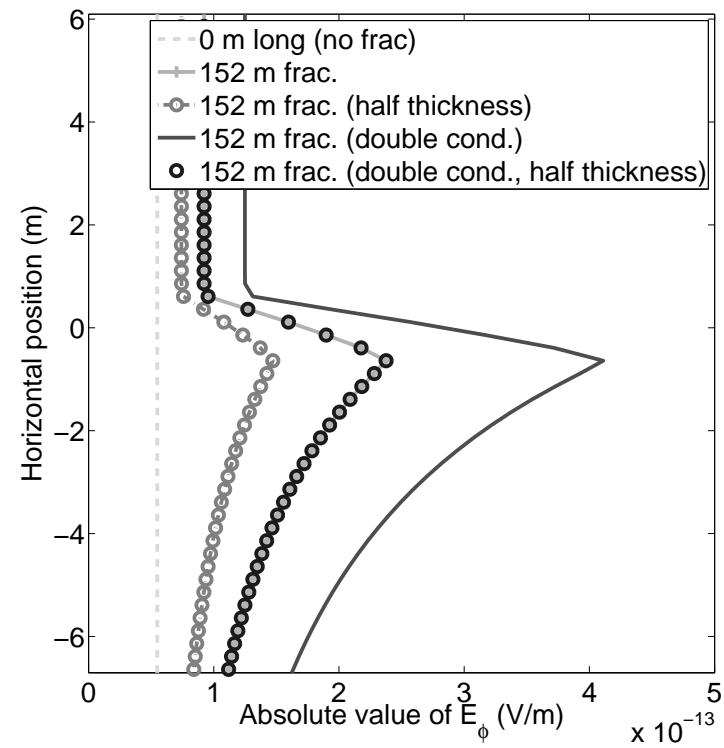

(c) Solenoids, coke breeze proppant $\left(3 \times 10^{-4} \Omega \cdot \mathrm{m}\right)$

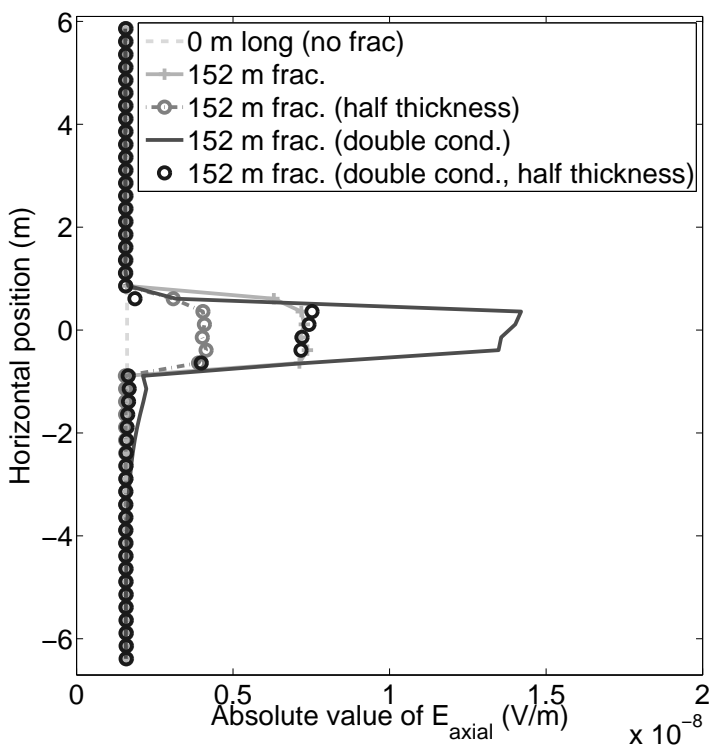

(b) Electrodes, sand proppant

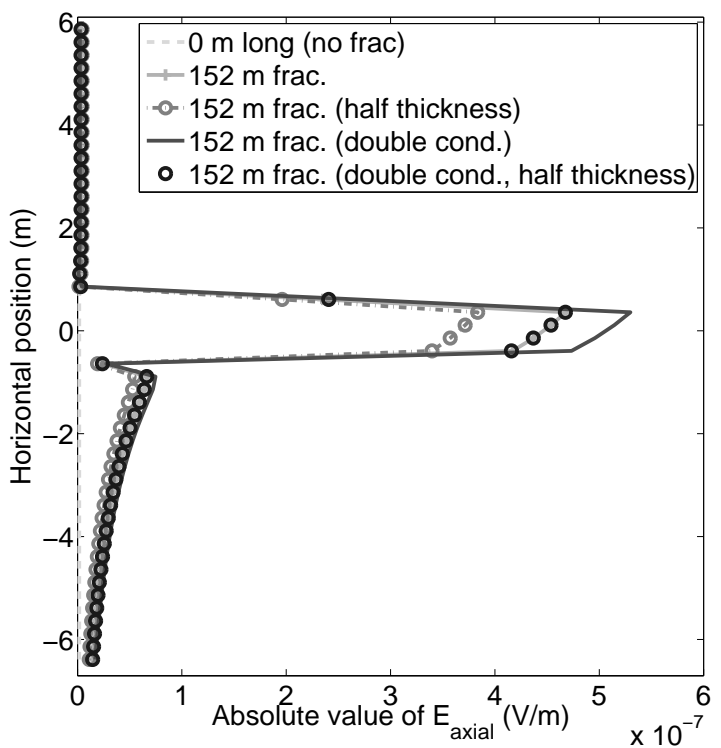

Figure 7: Sensitivity of different logging instruments to proppant thickness and resistivity. Frequency of operation: $100 \mathrm{~Hz}$. Background (shale) resistivity: $3 \Omega \cdot \mathrm{m}$. Spacing between transmitter and first receiver: $18 \mathrm{~m}$. Spacing between first and second receiver: $1.2 \mathrm{~m}$. 


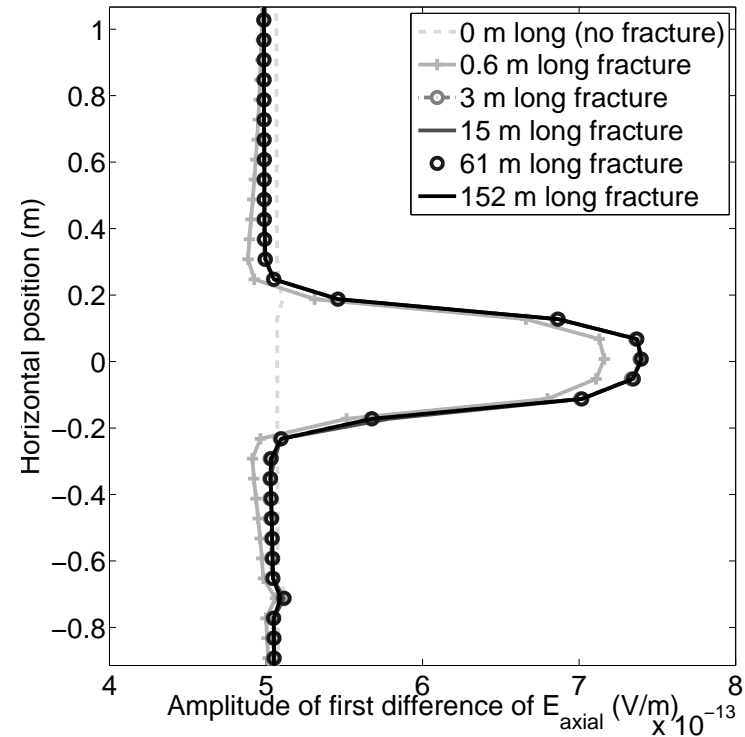

(a) Sand proppant, $1.2 \mathrm{~m}-0.3 \mathrm{~m}$ spacing

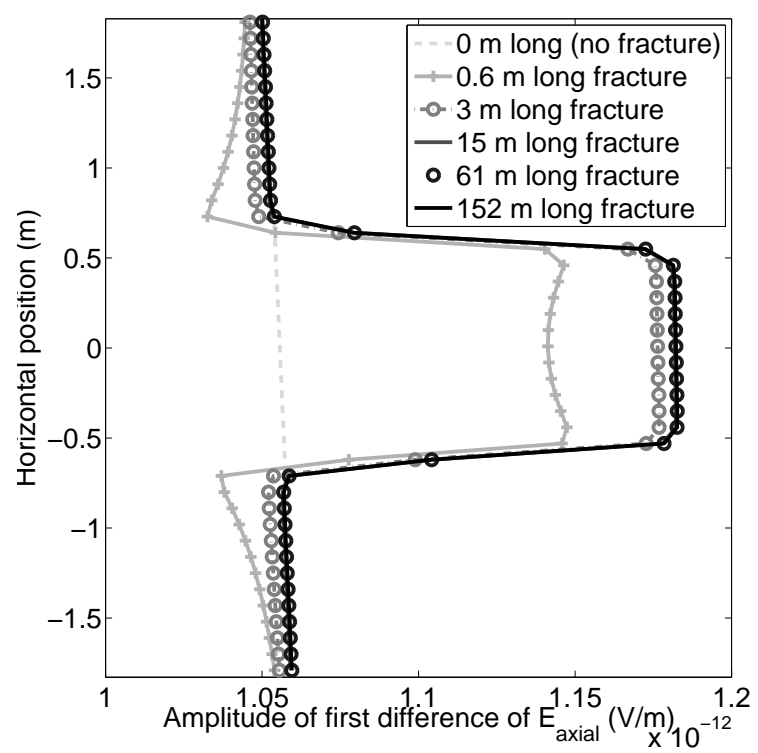

(c) Sand proppant, $18 \mathrm{~m}-1.2 \mathrm{~m}$ spacing

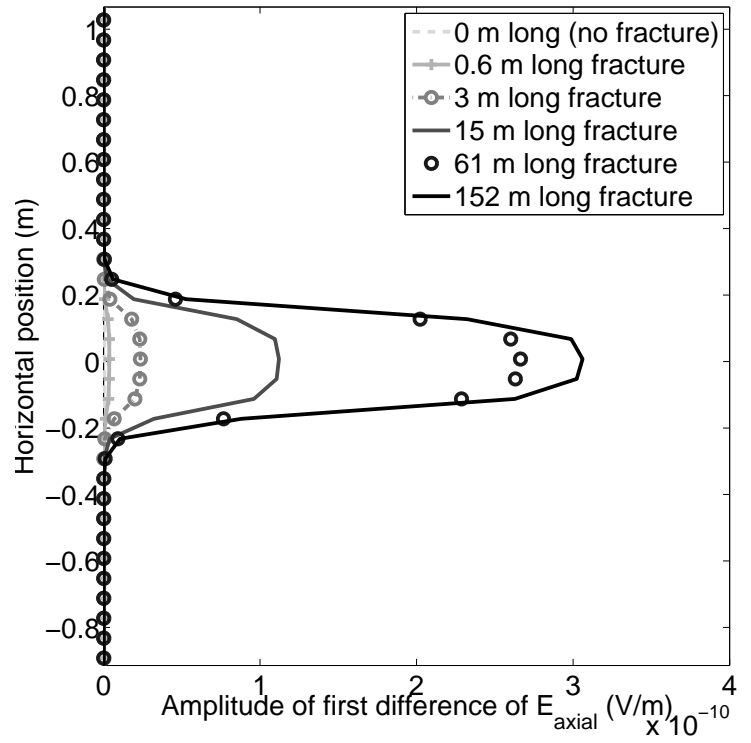

(b) Conductive proppant $\left(10^{-6} \Omega \cdot \mathrm{m}\right), 1.2 \mathrm{~m}-0.3 \mathrm{~m}$ spacing

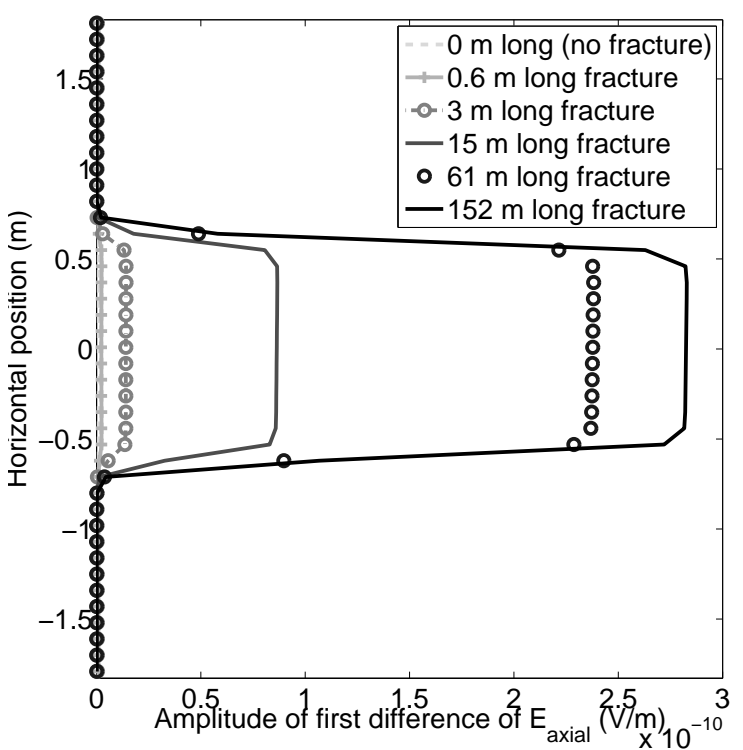

(d) Conductive proppant $\left(10^{-6} \Omega \cdot \mathrm{m}\right), 18 \mathrm{~m}-1.2 \mathrm{~m}$ spacing

Figure 8: Steel-cased well. Sensitivity of different logging instruments to hydrofracture length. Frequency of operation: $10 \mathrm{~Hz}$. Background (shale) resistivity: $3 \Omega \cdot \mathrm{m}$. 


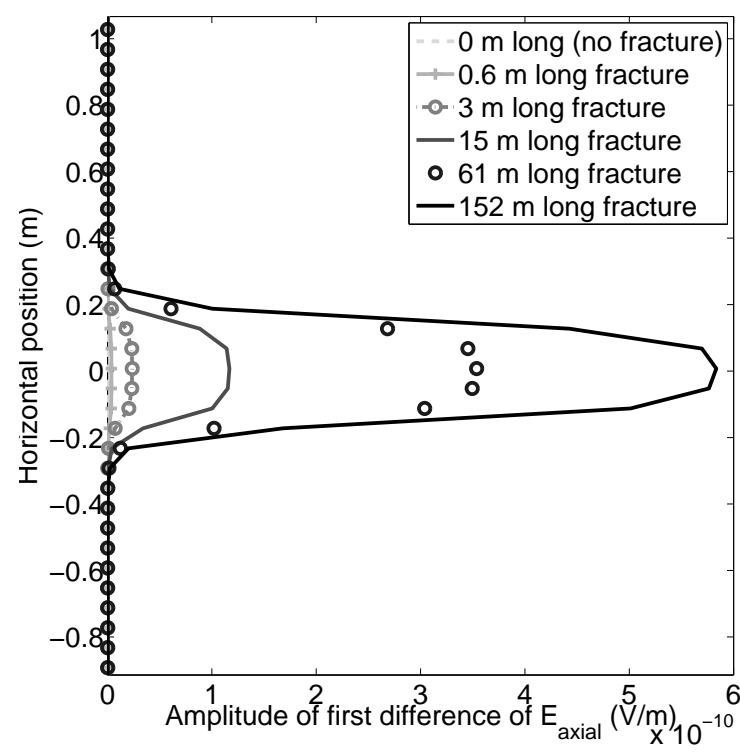

(a) $1 \mathrm{~Hz}$, background resistivity: $3 \Omega \cdot \mathrm{m}$

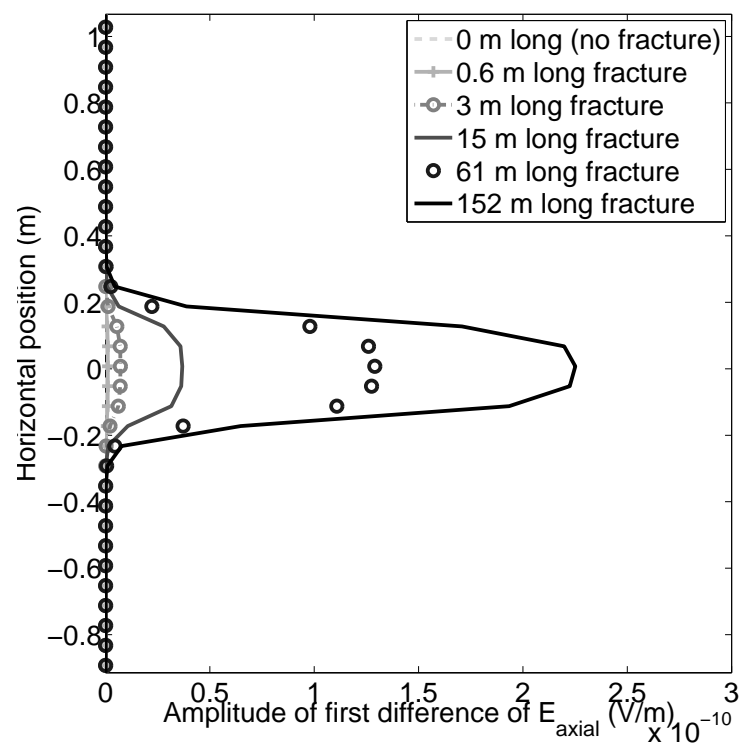

(c) $10 \mathrm{~Hz}$, background resistivity: $10 \Omega \cdot \mathrm{m}$

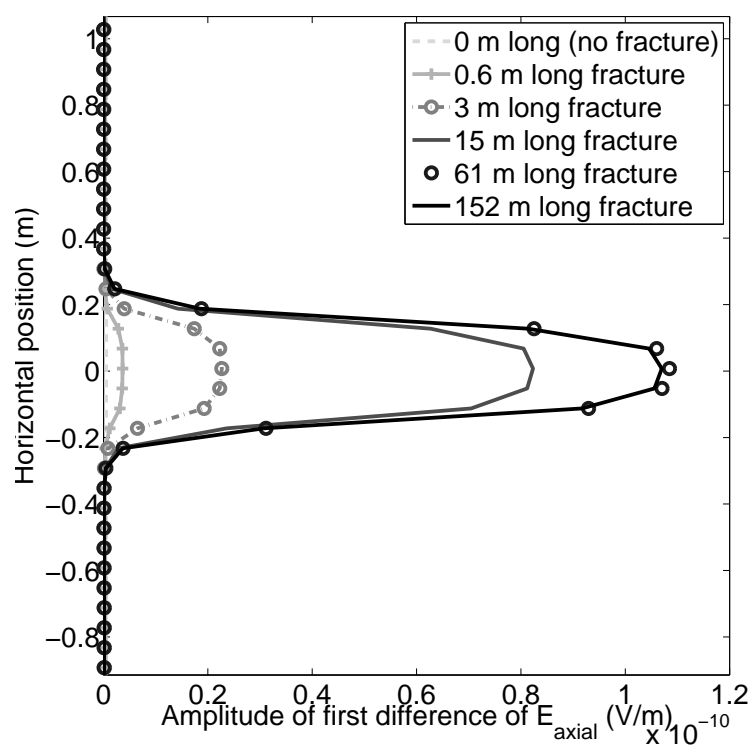

(b) $100 \mathrm{~Hz}$, background resistivity: $3 \Omega \cdot \mathrm{m}$

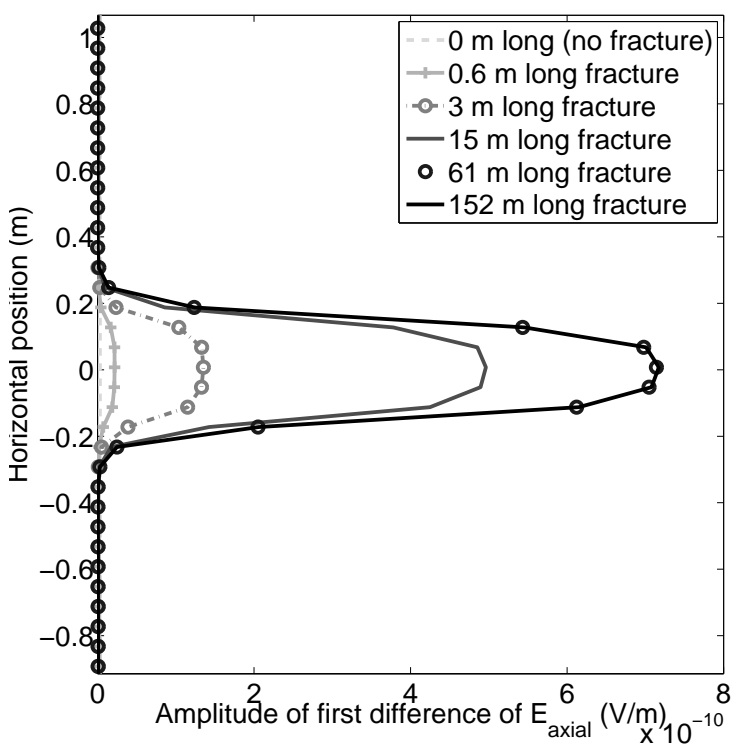

(d) $10 \mathrm{~Hz}$, background resistivity: $0.5 \Omega \cdot \mathrm{m}$

Figure 9: Steel-cased well. Sensitivity of different logging instruments to the length of a hydrofracture filled with electrically-conductive proppant $\left(10^{-6} \Omega \cdot \mathrm{m}\right)$. Spacing between transmitter and first receiver: $1.2 \mathrm{~m}$. Spacing between first and second receiver: $0.3 \mathrm{~m}$. 


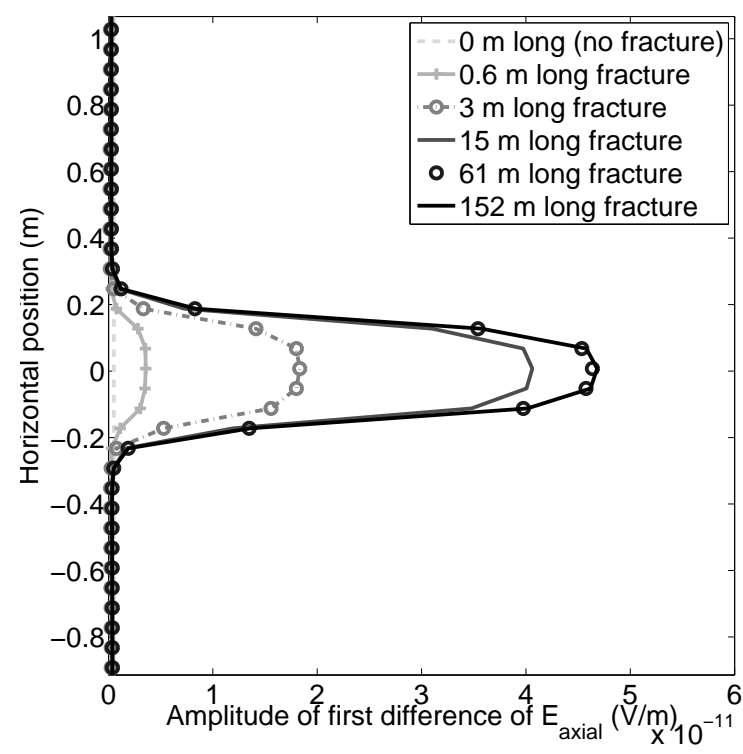

(a) $1 \mathrm{~Hz}$, background resistivity: $3 \Omega \cdot \mathrm{m}$

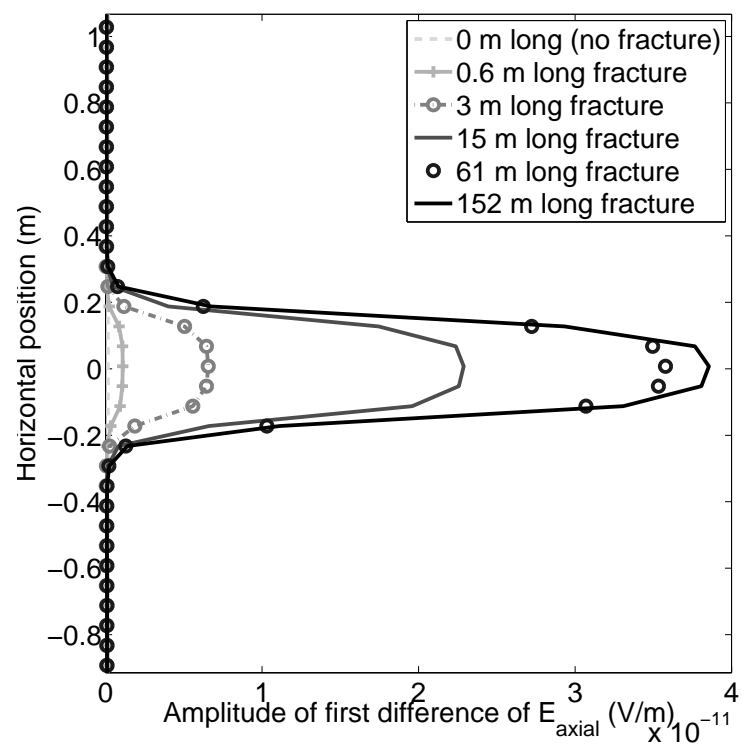

(c) $10 \mathrm{~Hz}$, background resistivity: $10 \Omega \cdot \mathrm{m}$

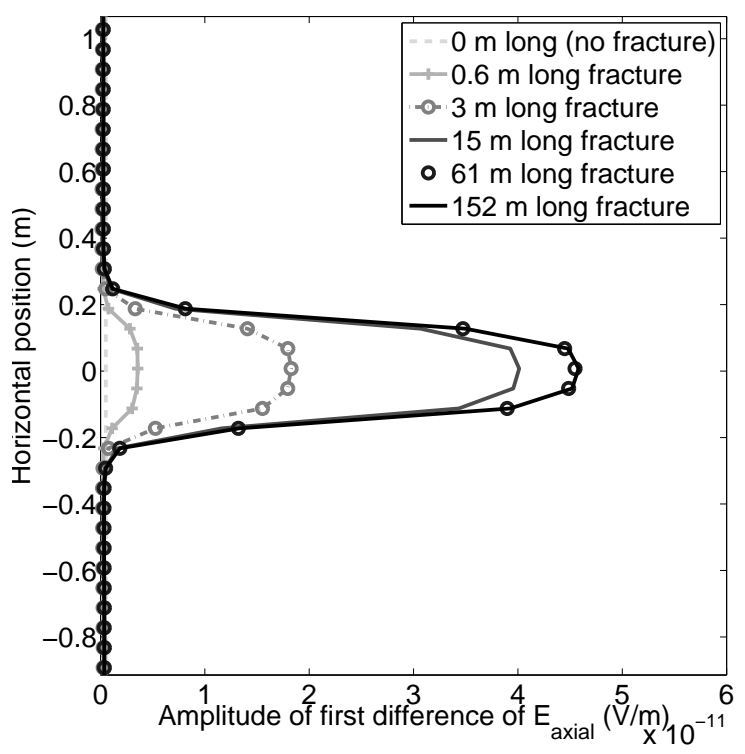

(b) $10 \mathrm{~Hz}$, background resistivity: $3 \Omega \cdot \mathrm{m}$

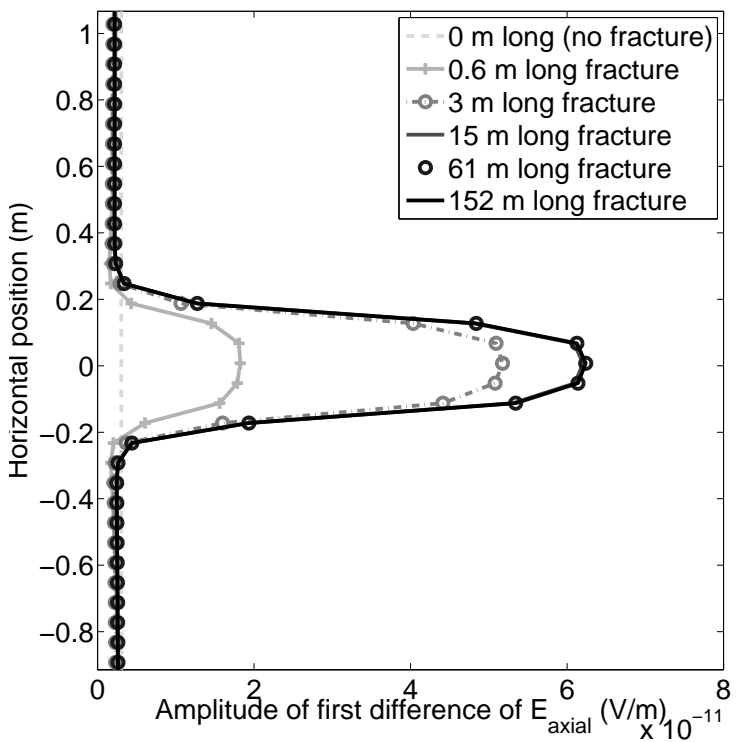

(d) $10 \mathrm{~Hz}$, background resistivity: $0.5 \Omega \cdot \mathrm{m}$

Figure 10: Steel-cased well. Sensitivity of different logging instruments to the length of a hydrofracture filled with coke breeze based proppant $\left(3 \times 10^{-4} \Omega \cdot \mathrm{m}\right)$. Spacing between transmitter and first receiver: $1.2 \mathrm{~m}$. Spacing between first and second receiver: $0.3 \mathrm{~m}$. 

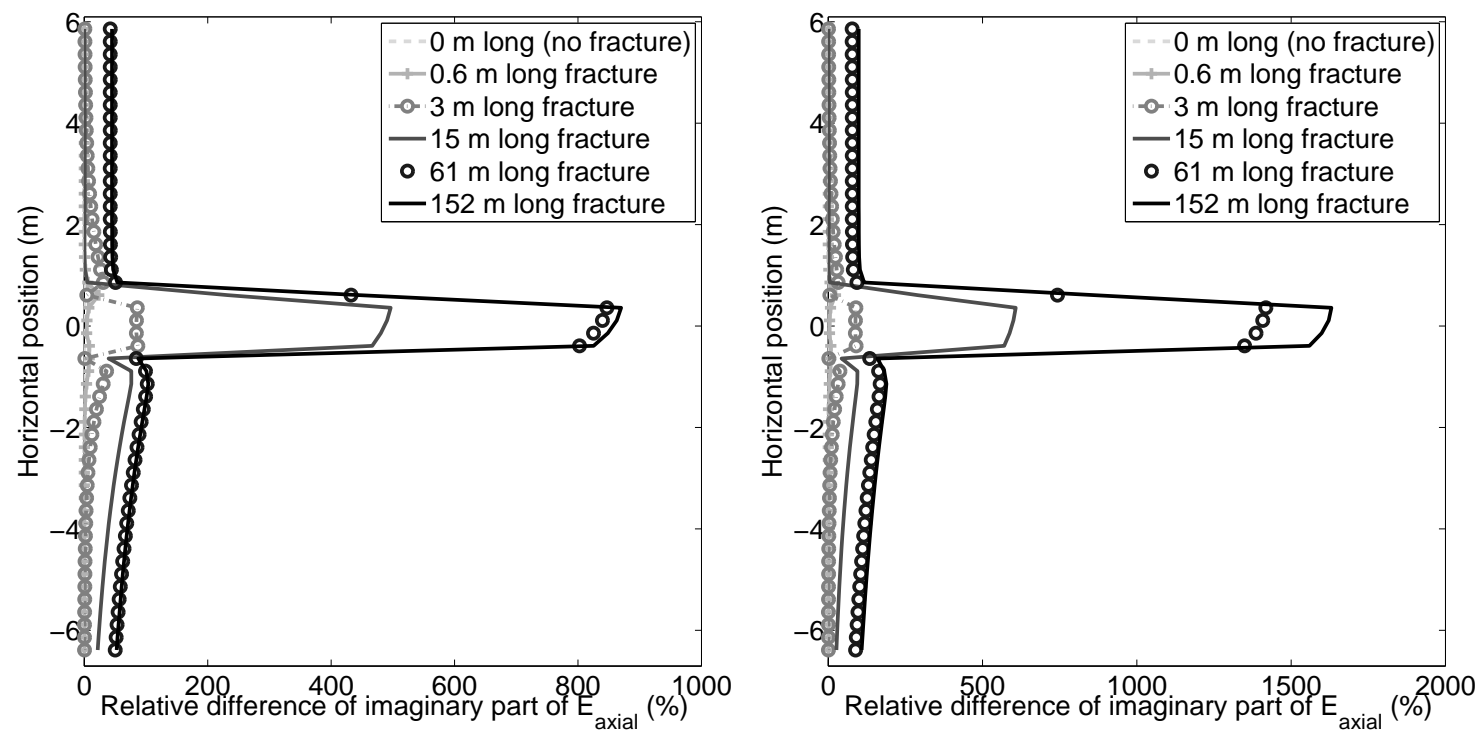

(a) Coke breeze proppant $\left(3 \times 10^{-4} \Omega \cdot \mathrm{m}\right), 18 \mathrm{~m}-1.2 \mathrm{~m}(\mathrm{~b})$ Highly conductive proppant $\left(10^{-6} \Omega \cdot \mathrm{m}\right), 18 \mathrm{~m}-$ spacing

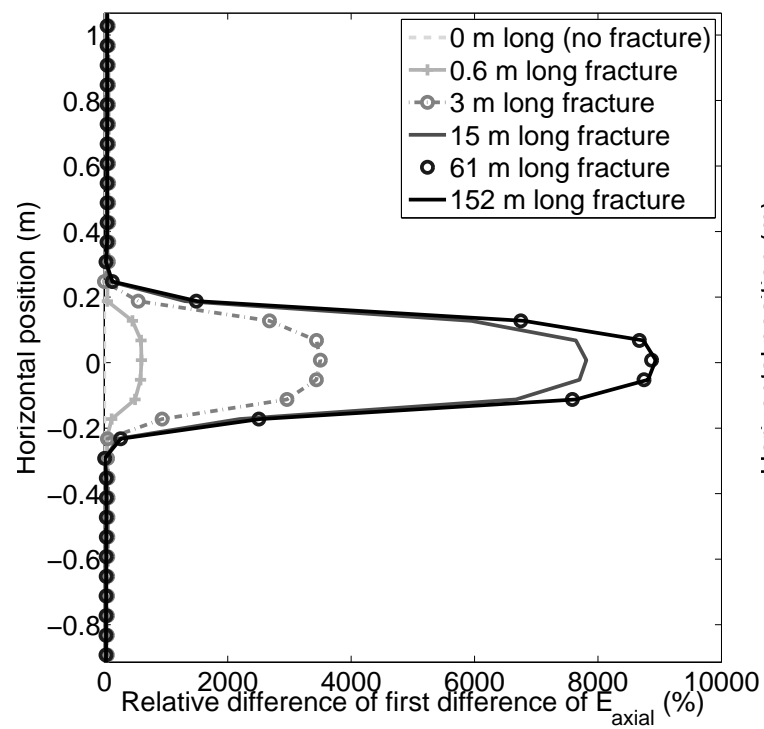

$1.2 \mathrm{~m}$ spacing

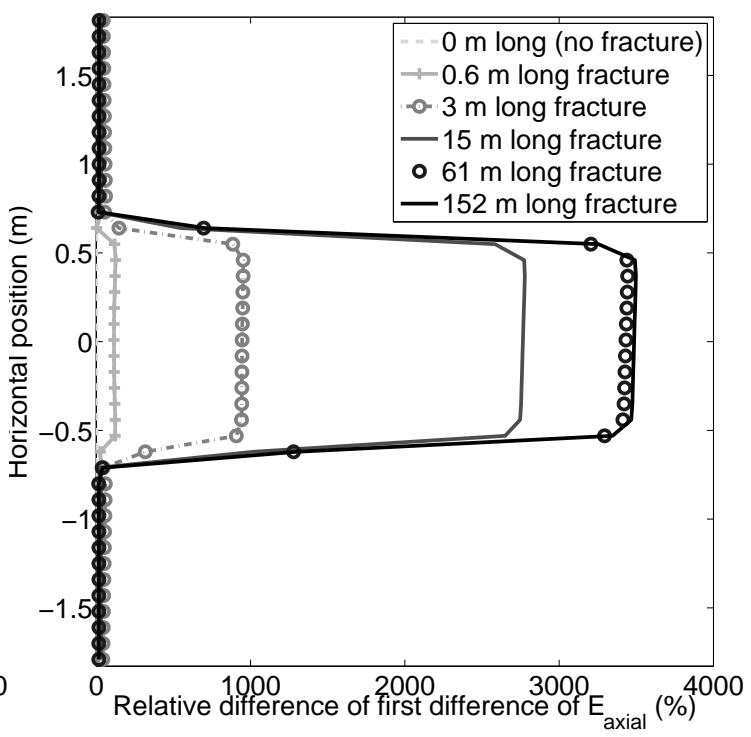

(c) Coke breeze proppant $\left(3 \times 10^{-4} \Omega \cdot \mathrm{m}\right), 1.2 \mathrm{~m}-0.3 \mathrm{~m}(\mathrm{~d})$ Coke breeze proppant $\left(3 \times 10^{-4} \Omega \cdot \mathrm{m}\right), 1.2 \mathrm{~m}-0.3 \mathrm{~m}$ spacing

spacing

Figure 11: (a,b) Open-hole well, $100 \mathrm{~Hz} . \quad(\mathrm{c}, \mathrm{d})$ Steel-cased well, $10 \mathrm{~Hz}$. Sensitivity of different logging instruments to hydrofracture length. Background (shale) resistivity: $3 \Omega$. m. 


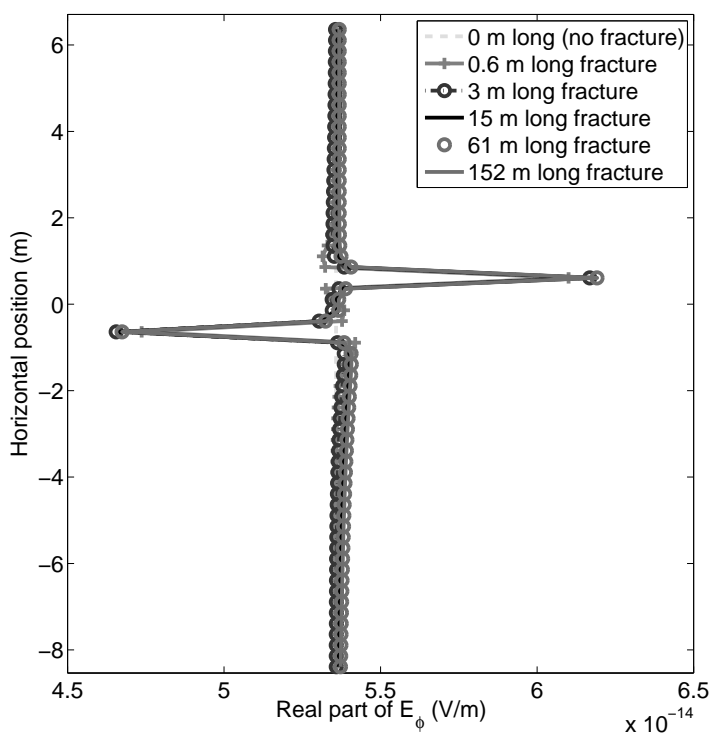

(a) Solenoids, real part

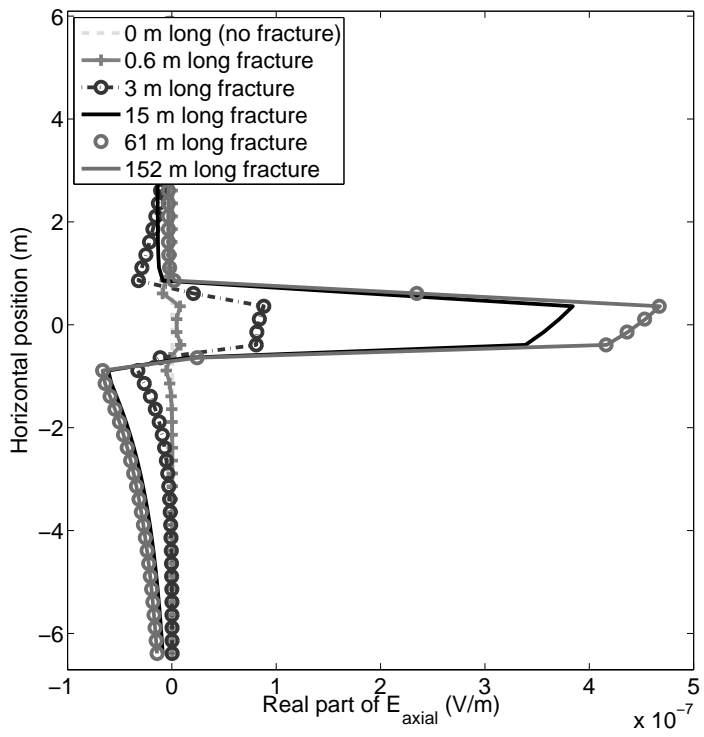

(c) Electrodes, real part

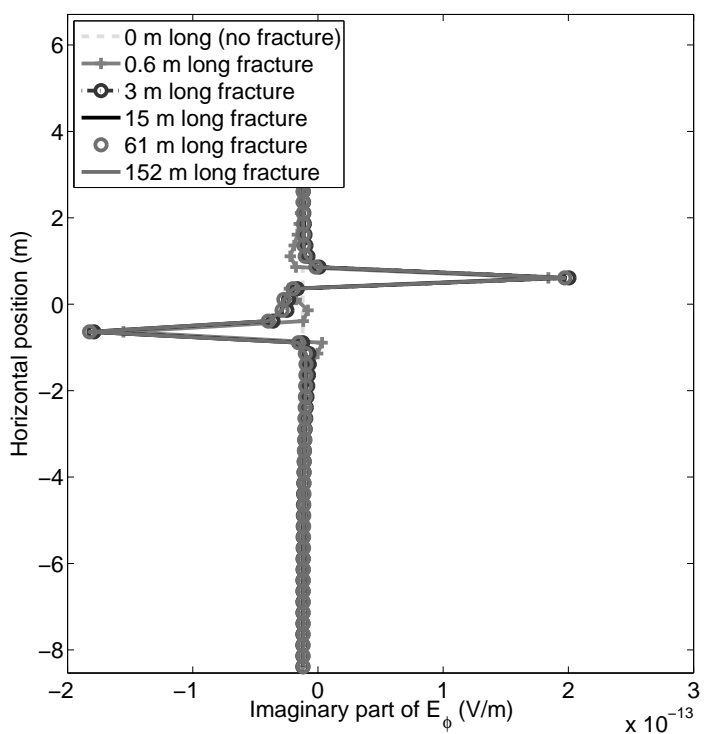

(b) Solenoids, imaginary part

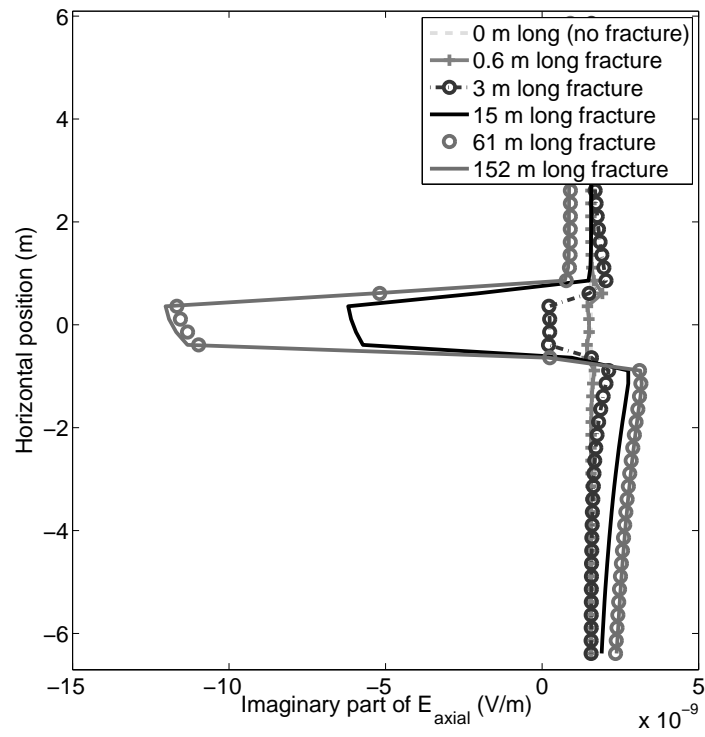

(d) Electrodes, imaginary part

Figure 12: Open-hole well. Sensitivity of different logging instruments to the hydrofracture length. (a,b) sand and ferrite based proppant. (c,d) coke breeze based proppant with ferrite. Frequency of operation: $100 \mathrm{~Hz}$. Background (shale) resistivity: $3 \Omega \cdot \mathrm{m}$. 